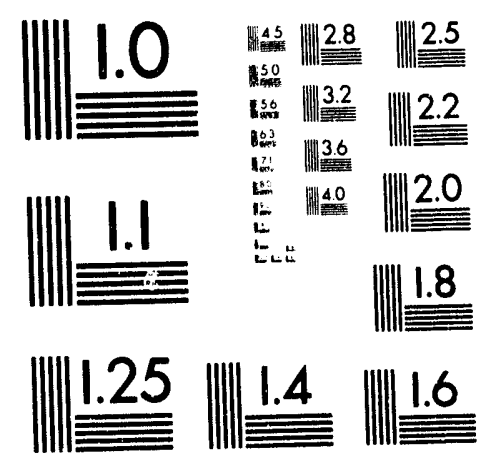



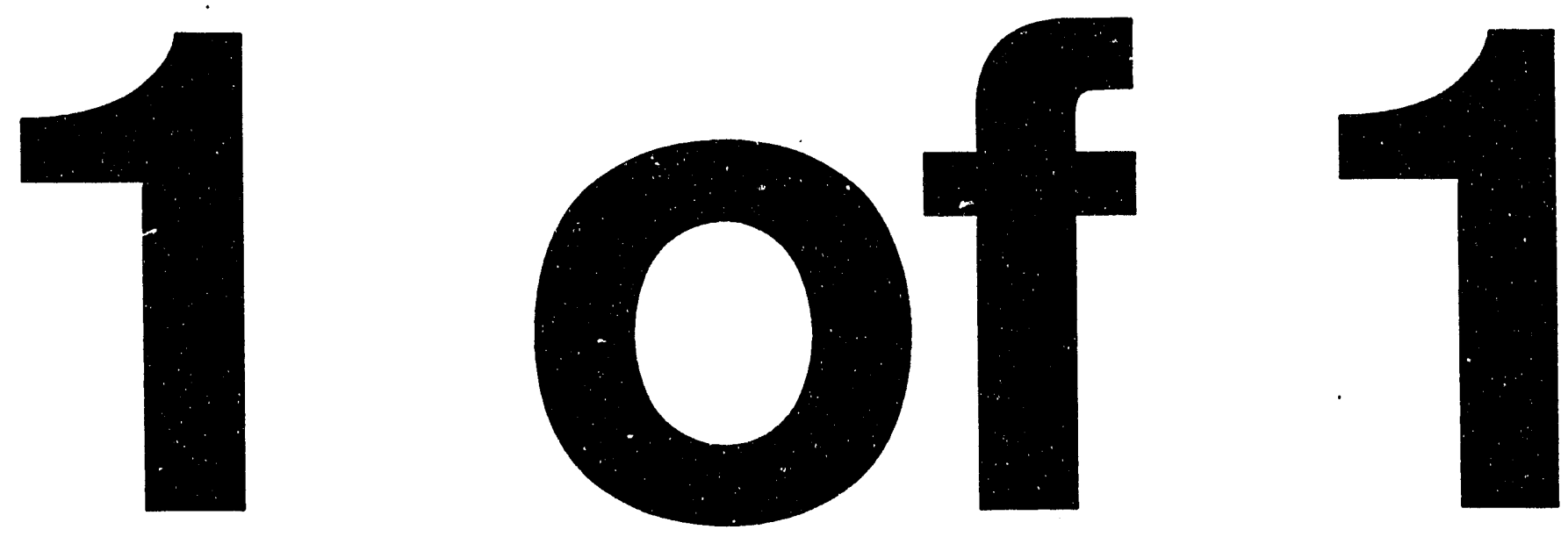
Physics Division

\title{
A REMOTE CONTROL CONSOLE FOR THE HHIRF 25-MV TANDEM ACCELERATOR
}

\author{
A. M. Hasanul Basher \\ Manuscript Completed-August 14, 1992 \\ Date Published-September 1993
}

NOTICE This document contains information of a preiiminaiy nature. It is subject to revision or correction and therefore does not represent a final report.

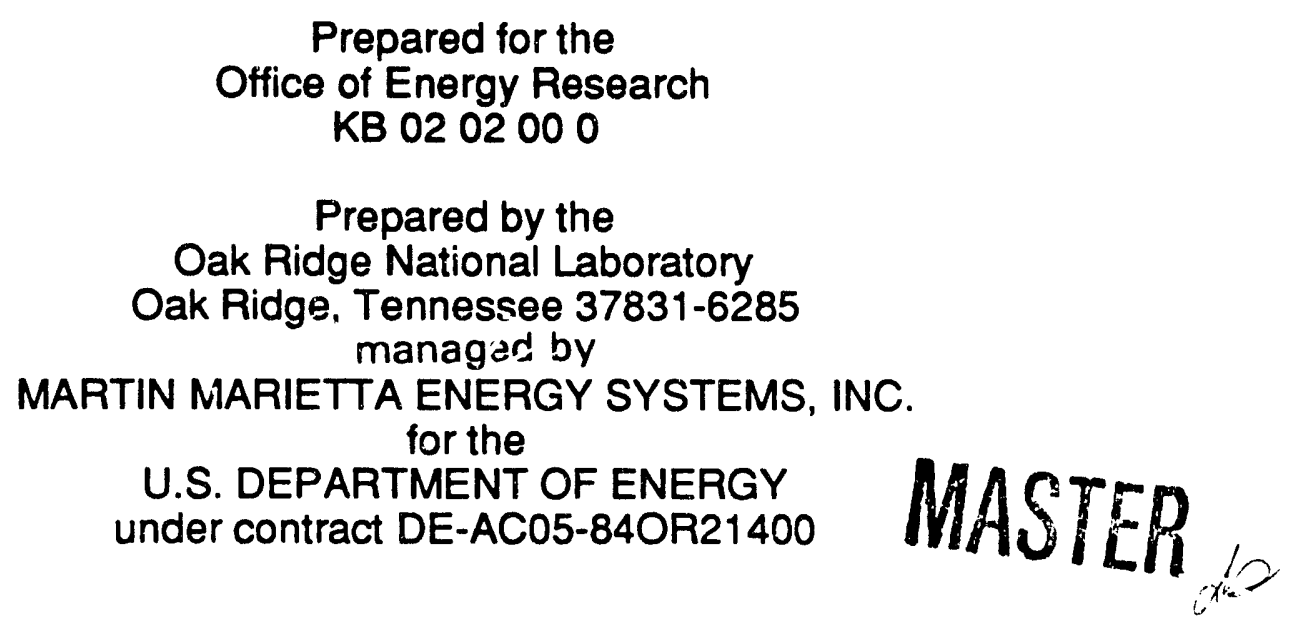




\title{
A REMOTE CONTROL CONSOLE
}

\section{FOR THE HHIRF 25-MV TANDEM ACCELERATOR*}

\author{
A. M. Hasanul Basher1 \\ Physics Division \\ Oak Ridge National Laboratory \\ Oak Ridge, Tennessee 37831-6368
}

August 14, 1992

" Operated by Martin Marietta Energy Systems, Inc. for the U.S. Department of Energy under contract No. DE-AC05-84OR21400.

1 Summer Faculty Research Participant, School of Engineering Technology, South Carolina State College, Orangeburg, South Carolina 29117. 
Page

Acknowiedgments

1. Introduction 1

2. Implementation Strategy 2

3. Work Completed 3

4. Future Action Plans 4

5. Data Transfer Protocol 5

6. File Structure and Program Execution 9

$\begin{array}{ll}\text { 7. Update CRT Page Text } & 17\end{array}$

$\begin{array}{ll}\text { 8. Flowcharts } & 21\end{array}$

Appendix

Program Listing 


\section{Acknowledoments}

This program was sponsored by Oak Ridge Associated Universities (ORAU) at Oak Ridge, Tennessee, and conducted under the supervision of Sigmund W. Mosko in the Physics Division at Oak Ridge National Laboratory. I greatly appreciate ORAU for giving me an opportunity to work on this project. I wish to express my gratitude to Sigmulid W. Mosko and Raymond C. Juras for their invaluable suggestions and tremendous help in carrying out this project. I also wish to express my gratitude to D. K. Olsen, Alan B. Tatum, Martha J. Meigs who helped me on mariy occasions by providing advice and discussing problems.

My thanks are due for helpful suggestions in preparing this report provided by Raymond C. Juras, Martha J. Meigs and B. Alan Tatum.

I greatly appreciate the help from several other members of the Physics Division who provided advice and helpful discussions.

I am also indebted to Ms. Jeanette McBride for her assistance in organizing and editing the report. 


\section{A REMOTE CONTROL CONSOLE FOR \\ HHIRF 25-MV TANDEM ACCELERATOR}

\section{INTRODUCTION}

The CAMAC-based control system for the 25-MV Tandem Accelerator at HHIRF uses 'wo Perkin-Elmer, 32-bit minicomputers: a message-switching computer and a supervisory computer. Two operator consoles are located on one of the six serial highways. Operator control is provided by means of a console CRT, trackball, assignable shaft encoders, and meters. The message-switching computer transmits and receives control information on the serial highways.

At present, the CRT pages with updated parameters can be displayed and parameters can be controlled only from the two existing consoles, one in the Tandem control room and the other in the ORIC control room. It has become necessary to expand the control capability to several other locations in the building. With the expansion of control and monitoring capability of accelerator parameters to other locations, the operators will be able to control and observe the result of the control action at the same time. This capability will be useful in the new Radioactive Ion Beam project of the division.

Since the new control console will be PC-based, the existing page format will be changed. The PC will be communicating with the Perkin-Elmer through RS232 with the aid of a communication protocol. Hardware configuration has been established, a software program that reads the pages from the shared memory, and a communication protocol have been developed. The following sections present the implementation strategy, work completed, future action 
plans, and the functional details of the communication protocol. The appendix contains the software programs developed in this phase.

\section{IMPLEMENTATION STRATEGY}

This project will be carried out in the following phases:

Phase I. Develop software that reads the shared memory of the PerkinElmer computer and correctly display each CRT page in the desired format.

Phase II. Develop a protocol that allows a PC to communicate with the Perkin-Elmer computer through RS-232. Develop software communication "layers" on the PC and the Perkin-Elmer computer to implement the protocol.

Phase III. Develop software that provides an operator with the following desirable features:

a. Dedicated display of pages on PC with parameters updated continuously with proper colors indicating the status of those.

b. Display assignable knobs and meters on PC with their labels wherever appropriate. 
c. Options to control different parameters with mouse and monitor them from PC.

\section{WORK COMPLETED}

In the first phase of the project, a software is developed that reads the shared memory of the Perkin-Elmer computer and displays each CRT page in the desired format. The program reads the contents of the selected page from the shared memory, calculates the value (both actual and percent of the value) and displays on the screen. In this new format, the page title, page number, and the date of the last page revision that are on the top three lines of the existing CRT page are displayed on the leftmost 16 columns on the PC screen. The accelerator parameters that start on the fourth line of the existing page are displayed, starting from the first line and in the 64 rightmost columns in the new format.

In this phase, a protocol is developed that allows the PC and the Perkin-Elmer to communicate with each other by sharing information. To implement the communication, separate software is developed for the PC and the PerkinElmer. Software for the PC is written in BASIC and that of the Perkin-Elmer is in FORTRAN. The transfer of requested data is accomplished via RS-232. Since the speed and the reliable transfer of data are very crucial, the amount of data transfer is kept to a minimum. The PC software sends the user-requested page number. The Perkin-Elmer software reads the page number. Then it calculates all values, finds color codes for the status fields, checks if a function is assigned, then prepares a file with this information and sends the file through the serial port via RS-232. The PC software reads the file and uses the information to 
update the parameter values, the status fields' colors and the assigned function color, and finally displays the page by calling the page text already saved in the PC's hard drive. The user can display a different page with updated parameters by entering a page number from the PC. In the first phase, active status parameters were indicated by printing an asterisk adjacent to the status field. Now this label is displayed in color by fetching the status information from the shared memory. The function assigned is also displayed in proper color. The parameter values and the status colors are updated continuously at a prsdetermined interval, while the page text remains static.

The FORTRAN program developed before is modified and is used to prepare the texts of the CRT pages from 0 through 99 in the new format, which is then transmitted to the PC with the help of KERMIT file transfer protocol. The user will only run a simple BASIC program. This program runs KERMIT and KERMIT then runs the FORTRAN program on the Perkin-Elmer. The FORTRAN program then prepares a file of page text in the new format. This file is then transmitted to the PC by KERMIT. All these can be done just by entering the name of the BASIC program. It will take a few minutes. Since the transfer of page text is not needed very often, the time required for the file transfer is not a major concern.

\section{FUTURE ACTION PLANS}

A program is now developed that will allow the user to update the page text whenever that becomes necessary. A protocol is also developed that allows the PC and the Perkin-Elmer to communicate with each other by sharing information. To display a CRT page, the page text is read from the PC hard drive and the other information, such as the parameter values and status fields' 
status colors, are received from the Perkin-Elmer with the aid of the protocol developed. In order to reduce the time required for data transfer and the chance of data being corrupted, the amount of data transfer is kept to a minimum.

Some additional monitoring and display of control parameters on the CRT pages, such as labels for assignable knobs and values for meters, are necessary. In the next phase, these will be completed. These will be displayed in the leftmost 16 columns of the PC screen below the line where the date is displayed. The user would be able to move the cursor to the appropriate label by means of a mouse and select it either for monitoring or controlling that parameter. If the label is selected for monitoring, the respective meter will display the value; but if it is selected for control, the function keys can be assigned to change the parameter at different rates. Then the parameter will be saved.

\section{DATA TRANSFER PROTOCOL}

A file or data is transferred from one computer to another (the PC and the Perkin-Elmer) by a pair of programs, one running on each computer. The programs carry out the data transfer process by sending messages to each other through their communication ports. This protocol is character-oriented, i.e., data is transmitted in the form of discrete characters. The data transfer is synchronized because the data sender waits for a response from the receiver after each character is sent. The sender sends a ready signal before the transmission starts to tell the receiver that data is ready to send. The receiver then sends back an acknowledge signal, indicating it is ready to receive data. 
The sender then sends data and waits for an acknowledge signal from the receiver before it sends the next data. Then the receiver sends the acknowledge signal after each character being received. This software handshake is necessary to avoid data overrun error during transmission. Since the speed of file transfer is one of the major concerns, the frequency of handshake is kept to a minimum. Since the Perkin-Elmer is slow in transmitting or receiving data to and/or from the outside devices, few delay loops are incorporated in the PC software to synchronize the timing between the two computers. The amount of delay is minimized by trial-and-error method.

The handshake process works like this: The transmitting computer sends a ready signal telling the receiving computer that it is ready to send data. The receiving computer sends an acknowledge signal. Then it waits for a while and checks the serial port to see if data is ready to read. After data is read, the receiving computer sends an acknowledge signal, advising the other computer to send more data. On the other hand, the transmitting computer waits for an acknowledge signal from the receiver before it starts sending data. Once the signal is received, the transmitting computer sends the first byte of data and sends the remaining bytes, one at a time, only after it receives the ackncwledge signal from the receiver. These two operations are shown below: 
Receiving Computer:

Wait for data ready signal

Receive:

Wait

Check port for data ready

Receive byte

Send acknowledge signal

Go to receive while more bytes to read

Transmitting Computer:

Send data ready signal

Send:

Send a byte

Wait for acknowledge signal

Go to send while more bytes to send

The following figures show how information transfer proceeds.

a. Send Page Number (PC to Perkin-Elmer):

PC Perkin-Elmer

Send ready signal ("\$")

Send first byte

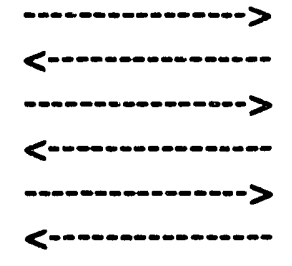

Send ack. signal ("?")

Send ack. signal ("?")

Send second byte

Send ack. signal ("?")

b. Parameter File Transfer (Perkin-Elmer to PC):

PC

Perkin-Elmer

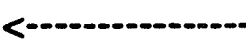

Send ready signal $\left({ }^{n * n}\right)$

(File is ready) 
Send ack. signal ("?")

Send ack. signal ("?")

Send ack. signal ("?")
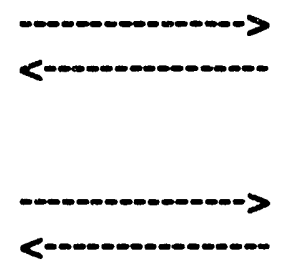

continue until the first line is transmitted

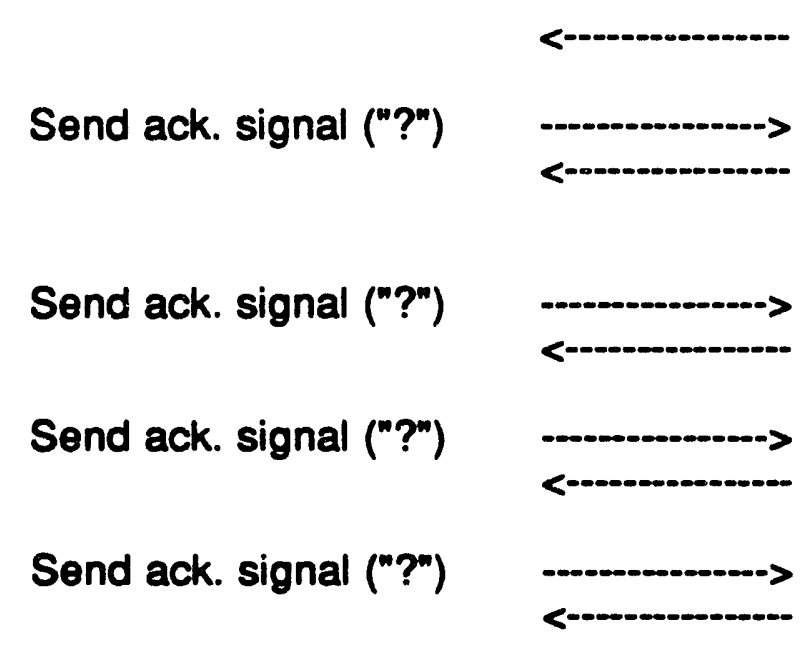

Send ack. signal ("?")

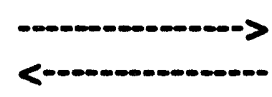

Send ack. signal ("?")

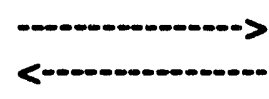

Send ack. signal ("?")

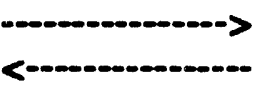

Send ack. signal ("?")
Send 2-digit character (One at a time. This is no. of lines in the file.)

Send 2-digit character (One ai a time. This is no. of characters in the second line of the file.)
Send 2-digit character (CRT line number)

Send character " $\mathrm{R}^{\text {" }}$ (If RESULT is present in the line)

Send character "P" (If PERCENT is present)

Send character " $S$ " (If SAVWRD is present)

Send character " $K$ " (If status field is present)

Send Function Assign Value ( 0 or 1 )

Send 9-character RESULT (If " $R$ " is sent)

Send 9-character PERCENT (If "P" is sent)

Send 9-character SAVWRD (If " $S$ " is sent) 
Send ack. signal ("?")

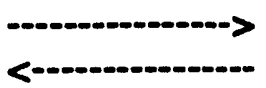

Send ack. signal ("?")

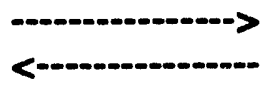

Send ack. signal ("?")

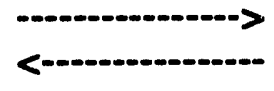

Send ack. signal ("?")

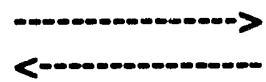

Send 1 character (If " $K^{n}$ is sent. This will be the number of status fields' labels.)

Send 2-character data (If " $\mathrm{K}^{\mathrm{N}}$ is sent. This is location of status field. Continue this for the number of status fields' labels.)

Send 2-character data (If " $K$ " is sent. This will be the color codes for each status field.

Continue this for the number of status fields' labels.)

Send End of File signal ("\$")

Send ack. signal ("?")

This will conclude the transfer of data. The characters such as $R, P, S$, and $K$ and their respective values will be transmitted only if these are present for a CRT line. If a CRT page does not have any parameter line, no such file needs to be transmitted and in that case, the Perkin-Elmer will send "\#" to the PC, indicating no file is created. The PC will then act accordingly.

\section{FILE STRUCTURE AND PROGRAM EXECUTION}

The user enters the CRT page number from the PC. Once the PC receives the page number, it sends it to the Perkin-Elmer through the serial port. The PerkinElmer then calculates parameter values and/or finds the status fields' labels' color 
codes and function assign status and then prepares a file to transfer to the PC. During this interval, the PC waits for a file ready signal from the Perkin-Elmer. The PC then receives the file with the aid of protocol via RS-232. The paragraphs below explain the structure of this file.

The first line of the file contains information such as the total number of lines in the file, number of characters in each of the following lines. A line is created for a CRT line if it has any of the parameters such as RESULT, PERCENT VALUE, SAVWRD and/or status field(s). The second to the last line of the file contains information about the CRT lines with parameters. The first two places of each of these lines in the file contain the actual CRT line number. The next few places are used for characters like $R, P, S$, or $K$, whichever is appropriate for that CRT line. If any of these is not appropriate for a CRT line, the corresponding character and it's value is not printed in the file. The character printed next is the function assign status. Next to this are printed the actual values of $R, P$, and $S$ (9 characters each), if present; then the number of status labels for $K$ ( 1 character), if present. If $K$ is printed, the next few characters printed in the file are locations of the status labels ( 2 characters each for $K$ number of labels) and the color codes for these labels ( 2 characters each for $\mathrm{K}$ number of labels)

The number of characters in each of the lines of the file of a CRT page with parameters can be calculated as follows:

Descriptions

CRT line number

Character "R"

Character "P"
Number of Characters

2

1 (if present)

1 (if present) 


$\begin{array}{ll}\text { Character "S" } & 1 \text { (if present) } \\ \text { Character "K" } & 1 \text { (if status field present) } \\ \text { Function Assign Status } & 2 \text { (0 or } 1 \text { ) } \\ \text { RESULT VALUE } & 9 \text { (if present) } \\ \text { PERCENT VALUE } & 9 \text { (if present) } \\ \text { SAVWRD } & 9 \text { (if present) } \\ \text { Number of Status Labels } & 1 \text { (if status field present) } \\ \text { Locations of Status Labels } & 2^{*} \text { (Number of Status Labels) } \\ & \text { (if status field present) } \\ \text { Color Codes } & 2^{*} \text { (Number of Status Labels) } \\ & \text { (if status field present) }\end{array}$

If all of the above are present in a line of a CRT page, the total number of characters in a line of the file after the first line is calculated as:

Totai Character $=36+4^{*}$ (Number of Status Labels)

If $N$ is the number of lines in a CRT page with parameters, the first line of this file will have $2^{*}(\mathrm{~N}+1)$ number of characters.

The PC reads the complete file, one character at a time, and prepares a similar file that contains all the lines except the first line. The information from the first line is used to arrange the file in the original format. It provides the PC information such as the total number of lines and the number of characters in each individual line.

The PC software then reads the text of the pages that are already saved in the PC and reads this new file, one line at a time. Once a match is found in the CRT line 
number in the two files, that line is updated with new parameters. Then, finally the page is displayed.

It is important to note that if a CRT page does not have any parameter, no file is created by the Perkin-Elmer. In that case, the Perkin-Elmer sends a special signal and the PC does not try to read the serial port; rather, it reads the page text and displays the page.

Figures 1 and 2 on the next page show the CRT page number 10 and the corresponding parameter file created by the Perkin-Elmer computer. This file is being used by the PC to update the parameters, status fields' colors and function assign status, which are discussed here. The first two characters of the file indicate the number of lines of the file and the pairs of characters that follow are the number of characters in each of the following lines. The second and the rest of the lines have similar structures. The first two characters carry the CRT page line number that contains any parameter. The above file indicates the first line of the CRT page 10 that has any parameter is 12 . The other lines of the page containing parameters are $13,14,18$, and 19. Next to the line numbers are characters such as $R, P$. $S$, and/or $K$. If $R$ is present in a line, that means this line has RESULTS, and so on. $P$ indicates the presence of PERCENT VALUE, $S$ stands for SAVWRD, and $K$ for status fields. The character that comes after this $(0$ or 1$)$ indicates if the function is assigned (1) or not (0). Next to this character are the actual values of $R$, $P, S$, and $K$ in the same order as their indicators are printed in the file. The values of RESULT, PERCENT, and SAVWRD each occupies 9 character positions, whereas $K$ occupies one (1) character position, since the value of $K$ is the number of labels present (maximum of 4). The line number 18 of this page has all 


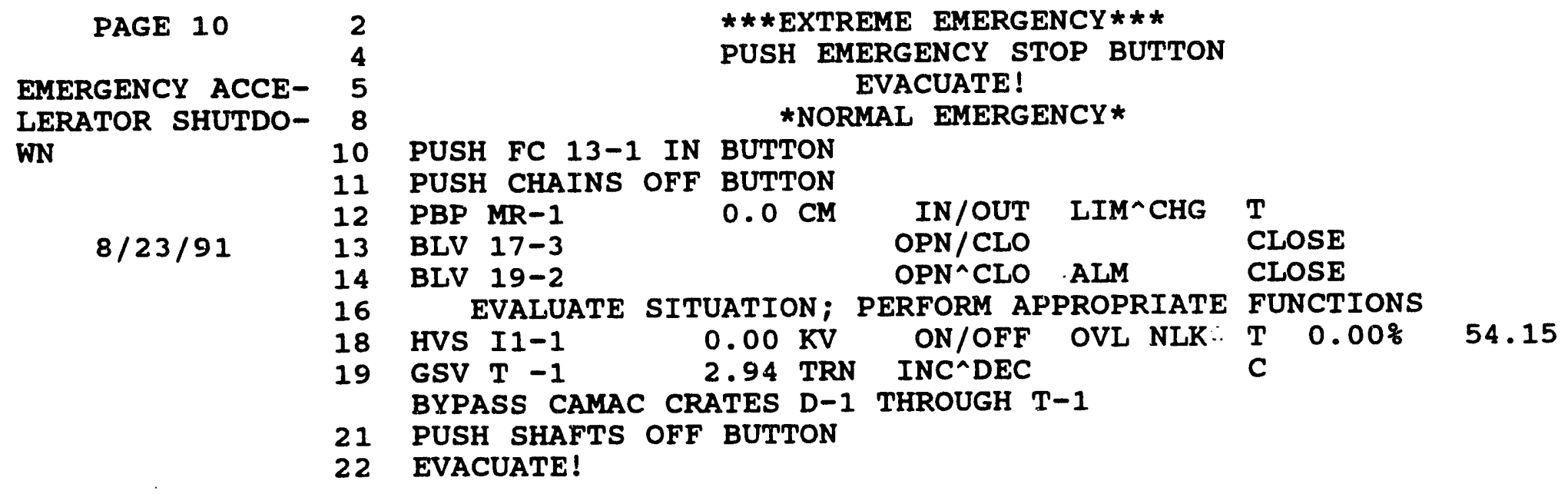

Figure 1

Parameter File

52814185224

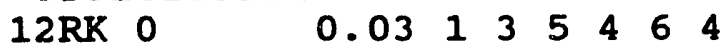

$\begin{array}{llllll}13 \mathrm{~K} & 02 & 1 & 3 & 4 & \mathrm{C}\end{array}$

$\begin{array}{lllllll}14 \mathrm{~K} & 03 & 1 & 3 & 5 & 4 & 442\end{array}$

$\begin{array}{llllllllllll}\text { 18RPSK } 0 & 0.00 & 0.008 & 54.15 & 4 & 1 & 3 & 5 & 7 & 4 & 6 & 242\end{array}$

19RK 0

3.0321344

Figure 2 
parameters and all four status fields' labels. After these, the line has actual status fields' label numbers and next are the color codes of these labels.

How the color codes are found and fetched from the shared memory, how the status fields' labels are determined, and their relations to the actual colors on the text are explained next.

The following global variables are needed:

POBUF (1,CRTLINE), POBUF (3,CRTLINE), BITBUF (1,CRTLINE), BITBUF (3,CRTLINE), BITBUF (5,CRTLINE), BITBUF (7,CRTLINE), TYPSAV (1,POINTER), BLCO2 (2,POINTER), DFBUF (1,CRTLINE), DFBUF (2,CRTLINE), DFBUF (3,CRTLINE), AND DFBUF (4,CRTLINE).

A CRT page can have, at most, two status fields with two labels in each. The labels are designated as $1,3,5$, and 7 , where labels 1 and 3 belong to status field 1 , and 5 and 7 to status field 2. Each label has one BITBUF that is used to find the status for the label. Four DFBUFs are there for the four labels. DFBUFs carry the color code for each label.

POBUF $(1$, CRTLINE) is for Status Field 1.

POBUF (3,CRTLINE) is for Status Field 2.

BITBUF (1, CRTLINE) is for Label 1.

BITBUF (3,CRTLINE) is for Label 3.

BITBUF (5,CRTLINE) is for Label 5.

BITBUF (7,CRTLINE) is for Label 7.

DFBUF $(1$, CRTLINE) is for Label 1. 
DFBUF (2,CRTLINE) is for Label 3.

DFBUF $(3$, CRTLINE) is for Label 5.

DFBUF $(4$, CRTLINE) is for Label 7.

The following calculations are done for the line number 18 of the CRT page 10:

Status Field 1, Label 1:

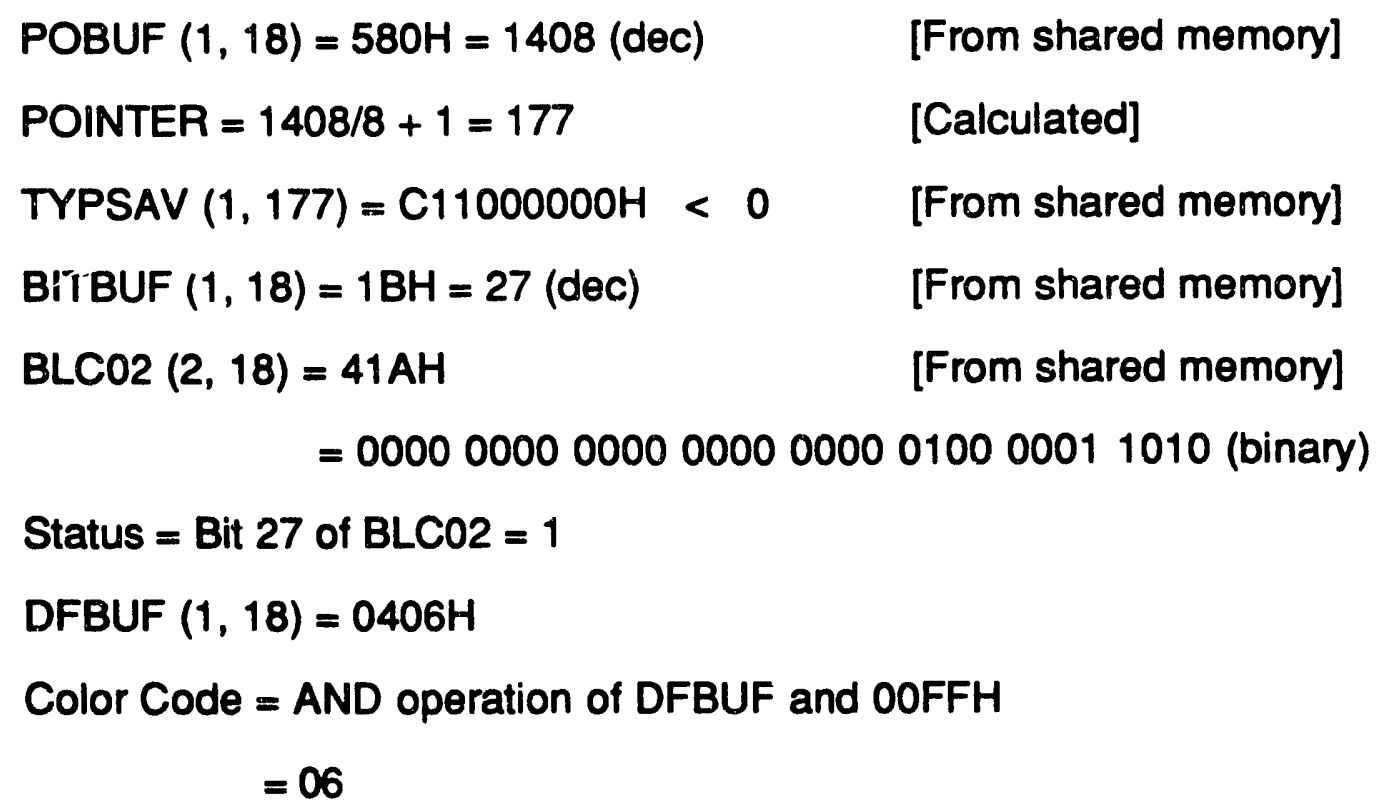

The first byte of this code is for background color and the second byte is for the foreground color. The actual color attribute is determined as

Color Attribute $=$ Color Code (Background Color)

Color Attribute $=$ Color Code $/ 2$ (Foreground Color)

Background Color Attribute $=0$

Foreground Color Attribute $=3$ 
Status Field 1, Label 3:

The POBUF, POINTER, TYPSAV and BLCO2 are same as above.

$\operatorname{BITBUF}(3,18)=$ FFEC $<0$

[From shared memory]

- BITBUF $(3,18)=0014 \mathrm{H}=20(\mathrm{dec}) \quad$ [Calculated]

Status $=$ Bit 20 of $3 L \mathrm{LO} 2=0 \quad$ [Calculated]

$\operatorname{DFBUF}(2,18)=0406 \mathrm{H}$

[From shared memory]

Color Code $=$ AND operation of DFBUF and FFOOH

$$
=04
$$

[Calculated]

Background Color Attribute $=0$

Foreground Color Attribute $=2$

The following table will demonstrate the actual color of the text.

$\begin{array}{cll}\begin{array}{c}\text { Attribute } \\ \text { (Decimal) }\end{array} & \begin{array}{c}\text { Foreground or } \\ \text { Background Color }\end{array} & \begin{array}{c}\text { Foreground Color with } \\ \text { Intensity Bit Set }\end{array} \\ 0 & \text { Black } & \text { Gray } \\ 1 & \text { Blue } & \text { Bright Blue } \\ 2 & \text { Green } & \text { Bright Green } \\ 3 & \text { Cyan } & \text { Bright Cyan } \\ 4 & \text { Red } & \text { Bright Red } \\ 5 & \text { Magenta } & \text { Bright Magenta } \\ 6 & \text { Brown } & \text { Yellow } \\ 7 & \text { White } & \text { Bright White }\end{array}$

With the help of this table, the actual colors of the above two labels can be found. The color of Label 1 of line 18 is cyan on black and that of Label 3 is green on 
black. In the existing CRT pages, the text color is green, so when the label color shows green, it is changed to the text color.

\section{UPDATE CRT PAGE TEXT}

The CRT page text for pages 0 through 99 can be updated with the aid of KERMIT file transfer protocol. The FORTRAN program (NEWPAGE.FTN) on se PerkinElmer computer will generate a file (PCPAGE.TXT) with page text which will be transferred to the PC with the aid of KERMIT with the same filename. The complete process will be done by running a small BASIC program on the PC. This program has filename UPDATE.BAS. The program destroys the old PCPAGE.TXT file and runs KERMIT. KERMiT runs NEWPAGE that creates updated page text. The PCPAGE.TXT file is then transmitted to the PC. Next, a BASIC program (CONVERT.BAS) is run again by KERMIT on the PC. The CONVERT program rearranges the file to make ready for display.

For successful operation of this file transfer process, the following programs are required:

On the PC:

1. UPDATE.EXE

2. CONVERT.EXE

3. KERMIT.EXE

4. MSKERMIT.INI

5. PAGETEXT 
Cn the Perkin-Elmer:

6. NEWPAGE.EXE

File Created:

PCPAGE.TXT 
The listing of programs required for this file transfer are given here:

1. UPDATE.BAS

CLS

KILL "PCPAGE.TXT"

RUN "KERMIT"

END

2. CONVERT.BAS

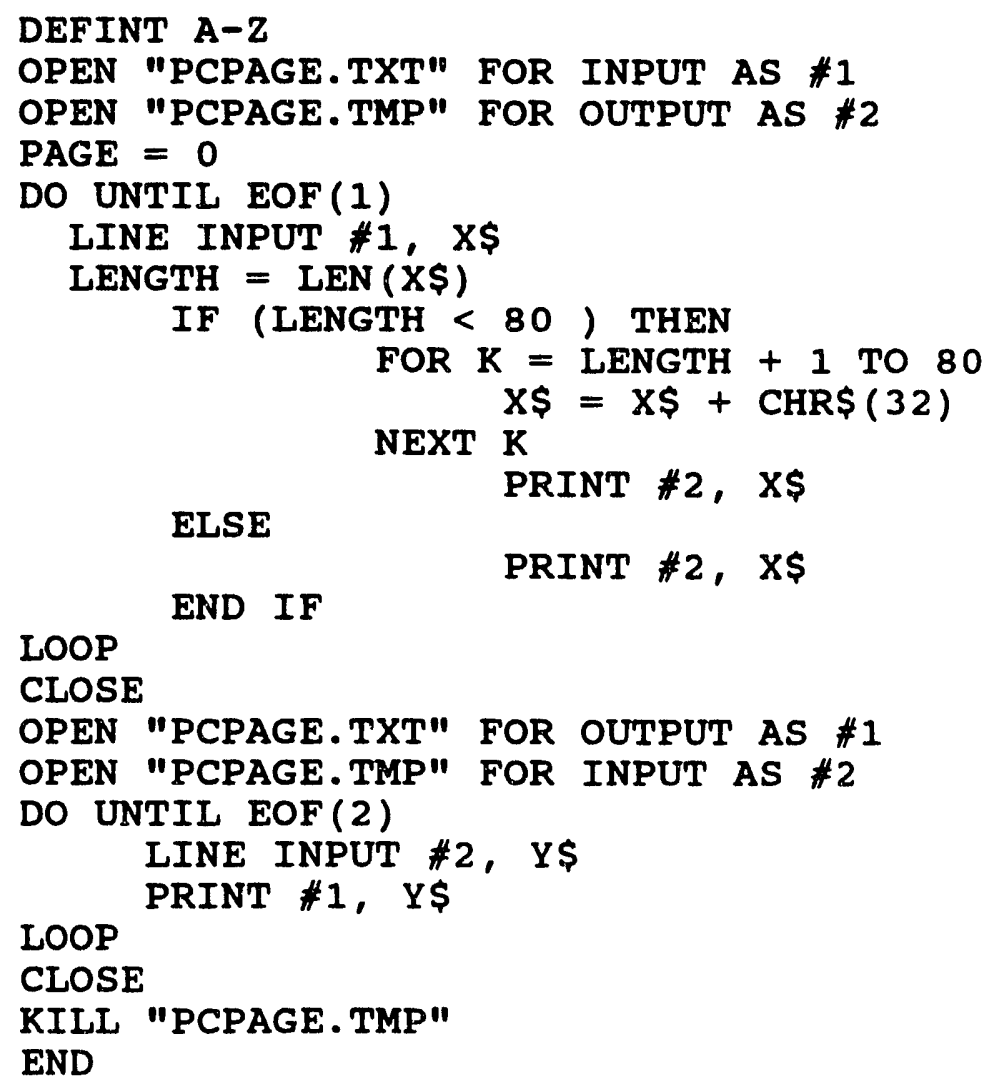


3. MSKERMIT.INI

\author{
SET PORT 1 \\ SET SPEED 9600 \\ SET PARITY EVEN \\ TAKE PAGETEXT
}

\title{
4. PAGETEXT
}

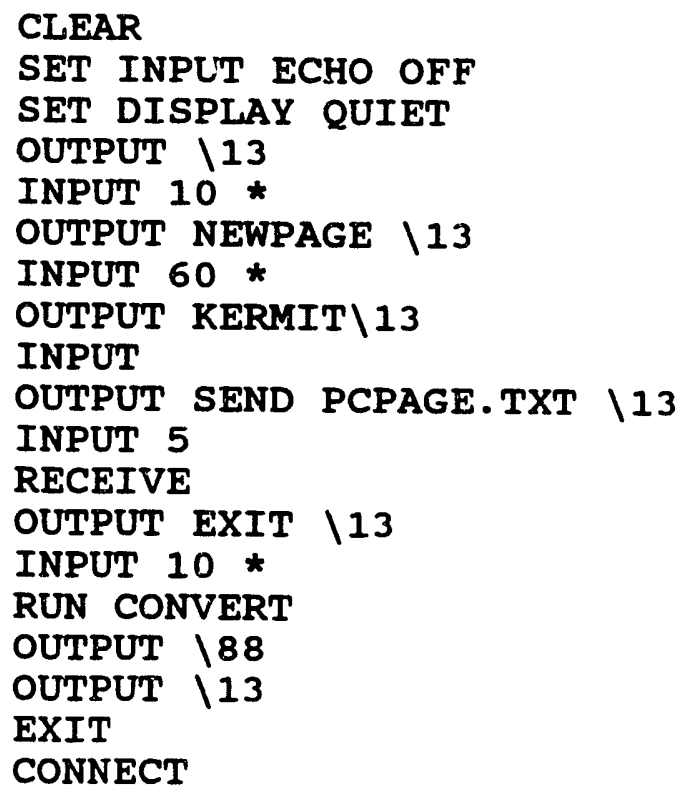


Command needed to update the page text and transfer to the PC is:

At the Prompt Type: UPDATE

Sign-on to Perkin-Elmer prior to issuing this command is required. For automatic sign-on, the following additional commands are needed in the KERMIT script file PAGETEXT. After the command "SET DISPLAY QUIET" it is needed to add:

OUTPUT / 13

OUTPUT user rode

INPUT 10 *

\section{FLOWCHARTS}

The next fow pages display the following flowcharts:

1. Prepare Parameter File (Perkin-Elmer).

2. Page Display on PC.

3. Communication Protocol (Perkin-Elmer).

4. Communication Protocol (PC, Send Page Number).

5. Communication Protocol (PC, Read Parameter File).

The page number is sent by the PC to the Perkin-Elmer. After reading the page number, the Perkin-Elmer prepares a parameter file which is sent to the PC. The $\mathrm{PC}$ reads the parameter file. Then the $\mathrm{PC}$ reads the text of the page from its 
hard drive, displays the text, and uses the parameter file to update the parameters on the page. 
PaEPARE PARAMETER FILE

PFRKIN-EMMER

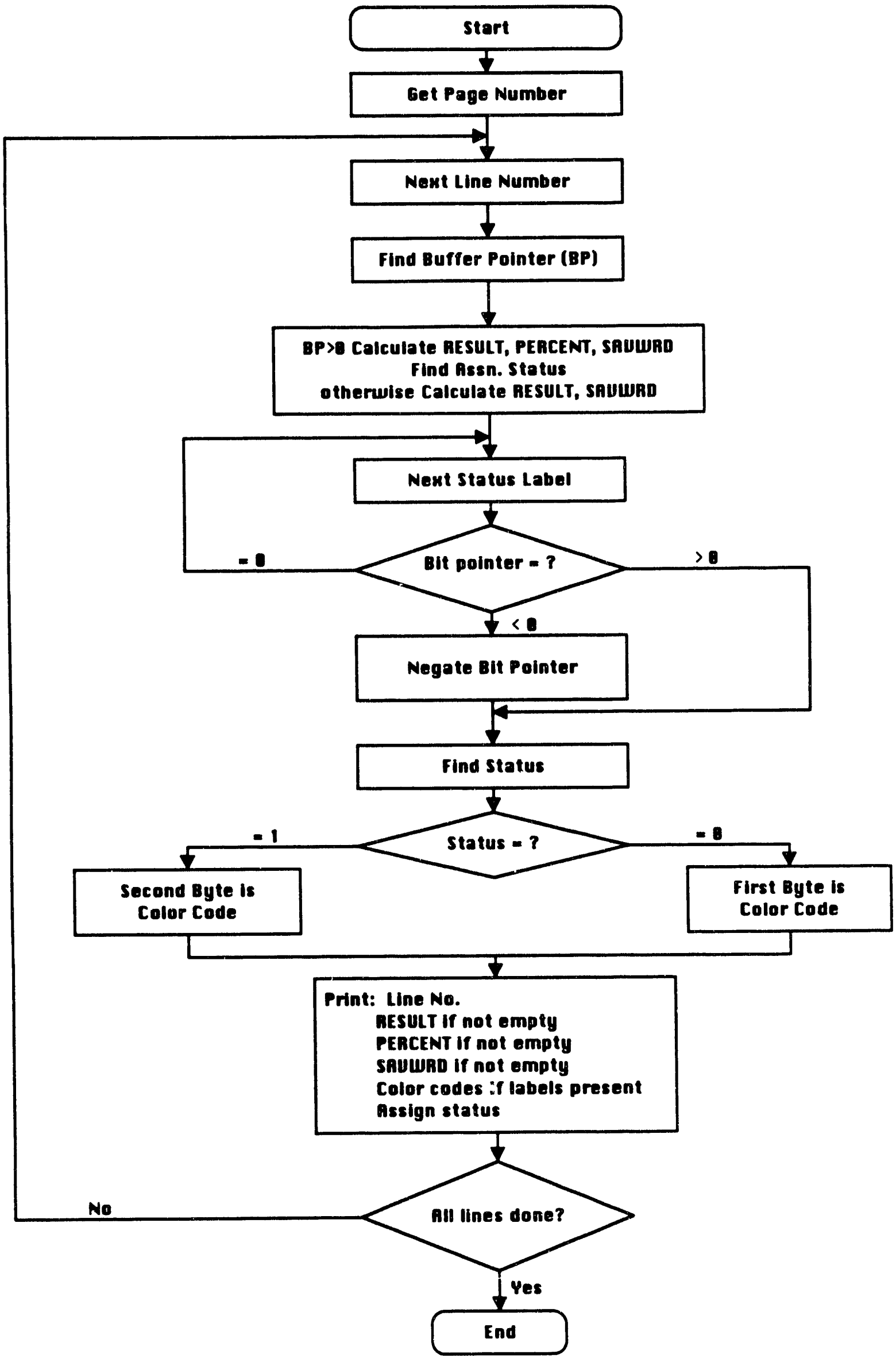




\section{Pafe nISPlaY}

nNeC

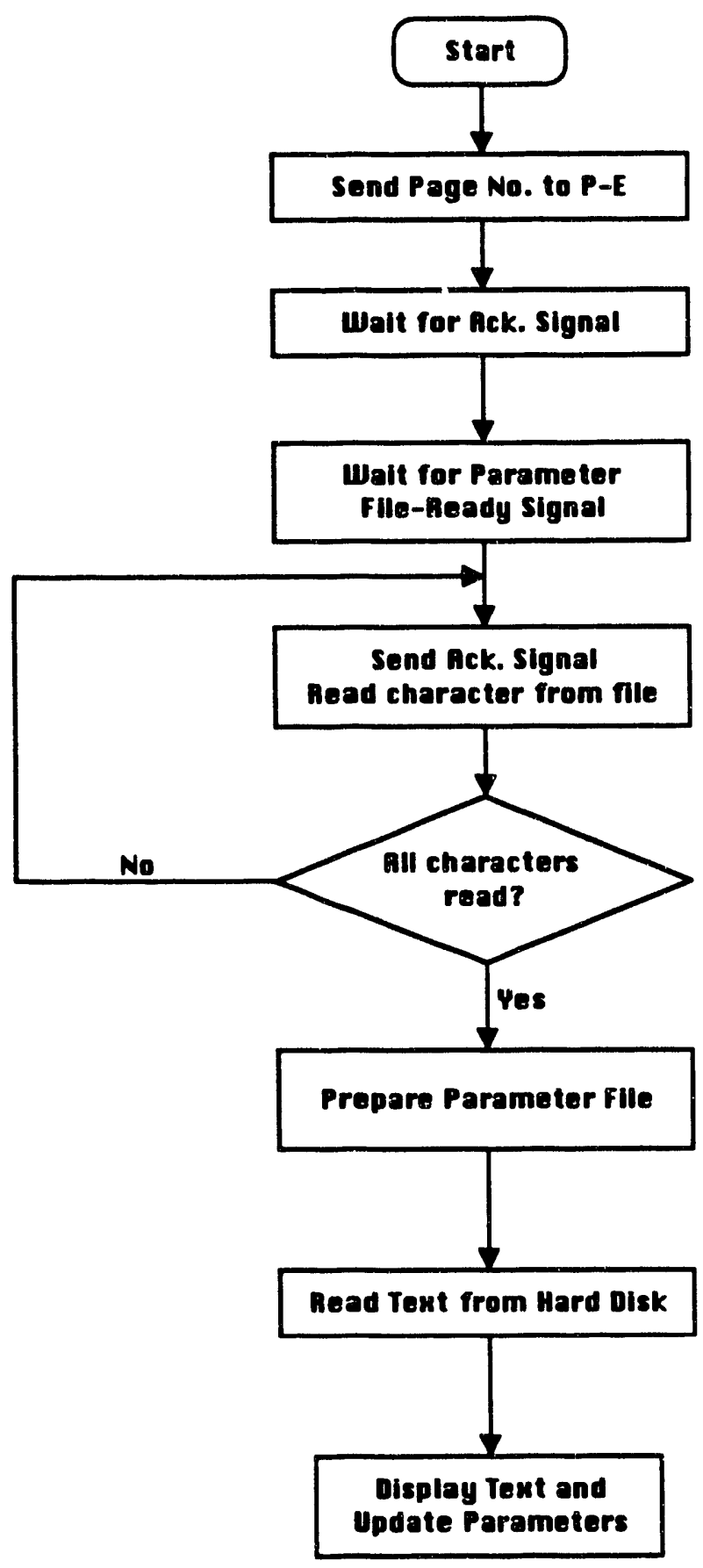




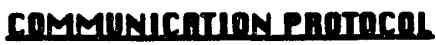
CEAKIN-EIMER

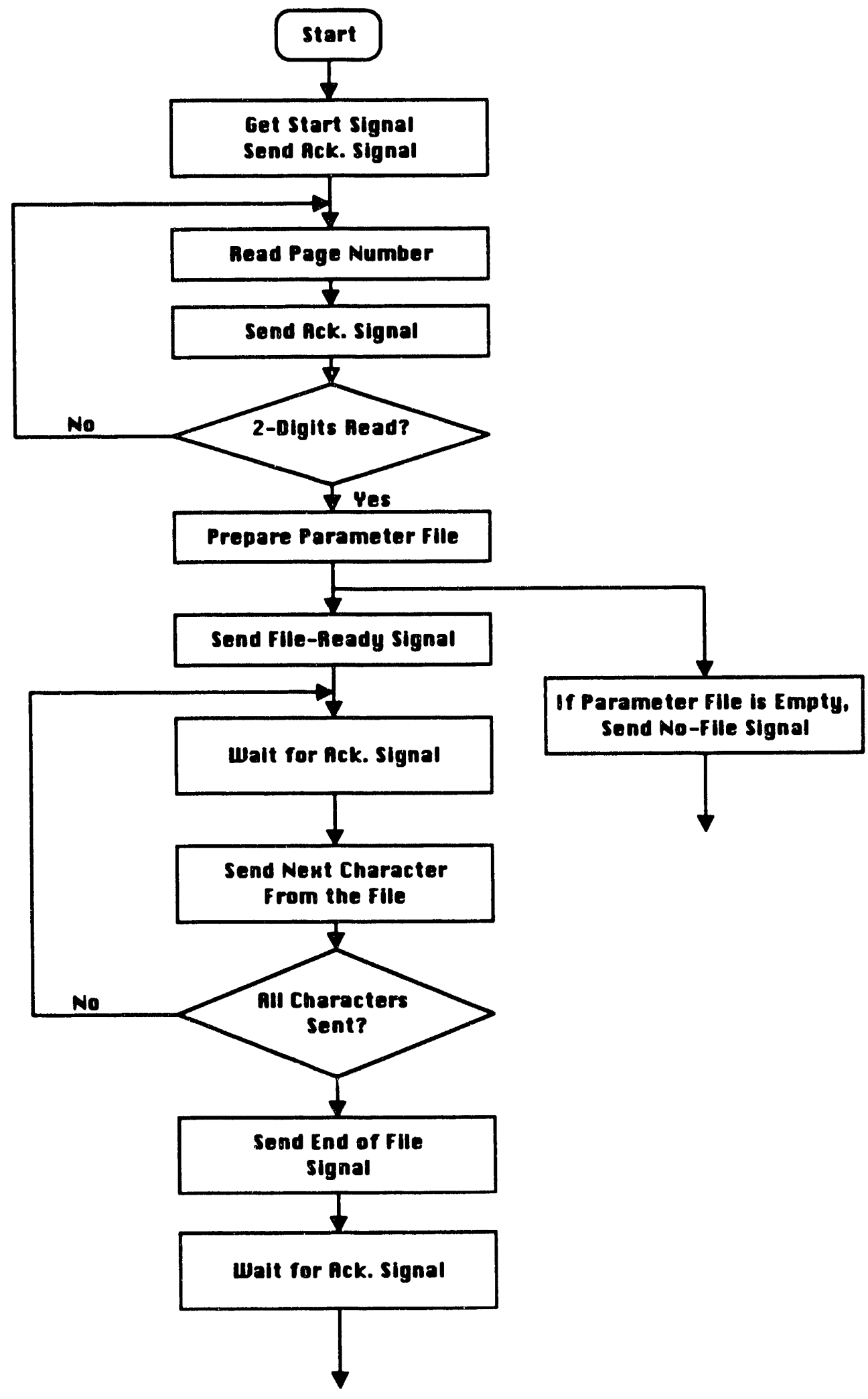


ISOMMUNICATION PROTOCOL

PC

SEND PAGE NUMBER

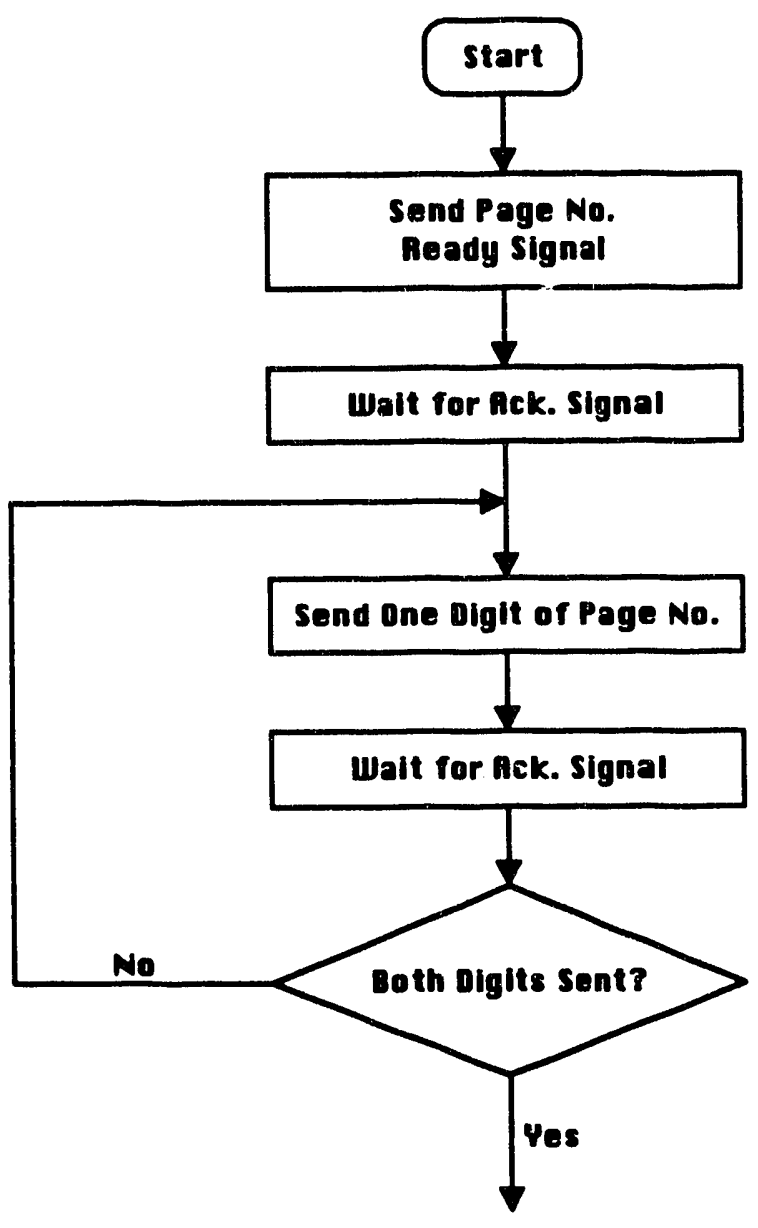




\section{COMMUNICATIONEATIOCOL}

ec

AEAO PARAMETER EILE

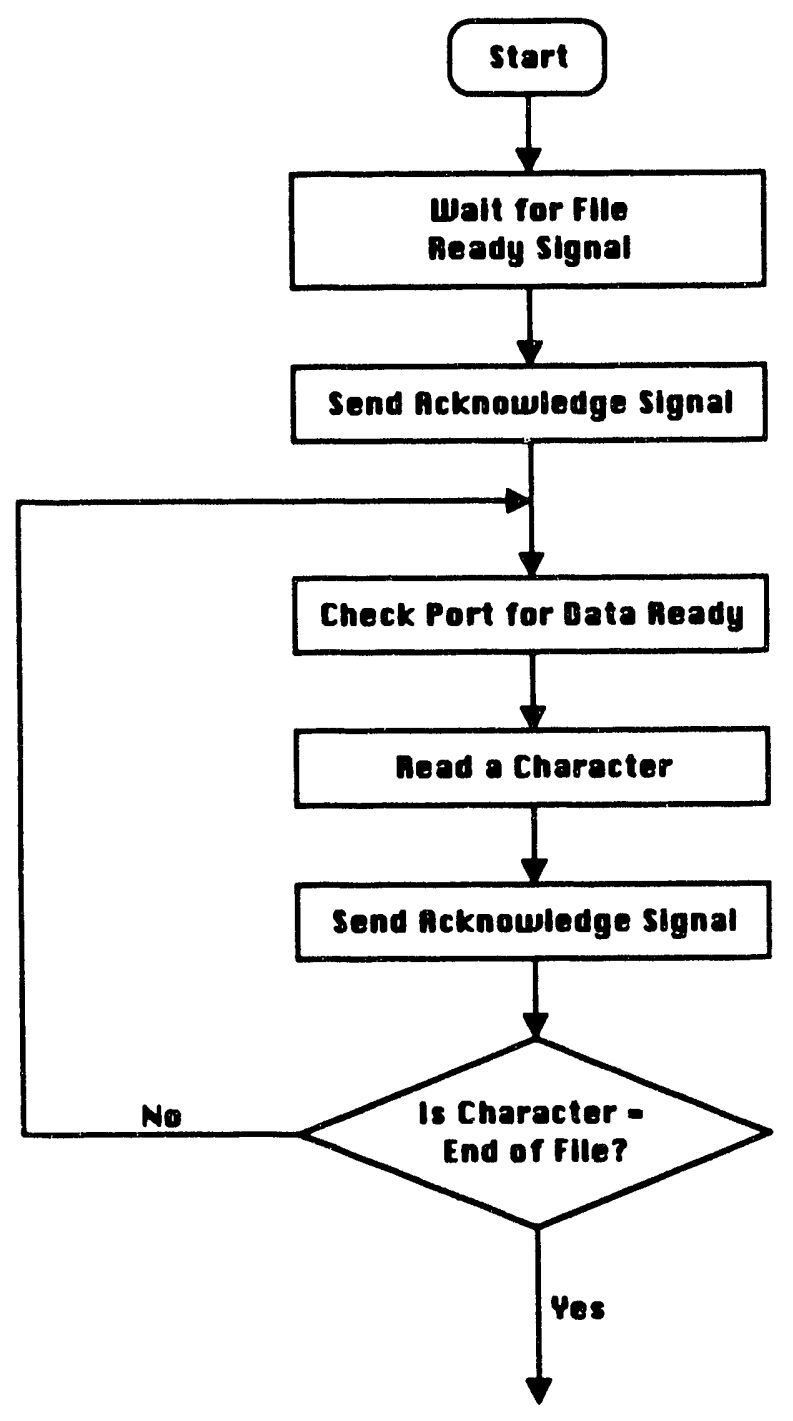




\section{APPENDIX}

The following pages contain the program listings that are developed in this phase of the project. Two different programs that run on the two computers (PC and Perkin-Elmer) allow them to communicate with each other by exchanging data from one to the other. The program on the PC is written in BASIC and the one that runs on the Perkin-Elmer is written in FORTRAN. 


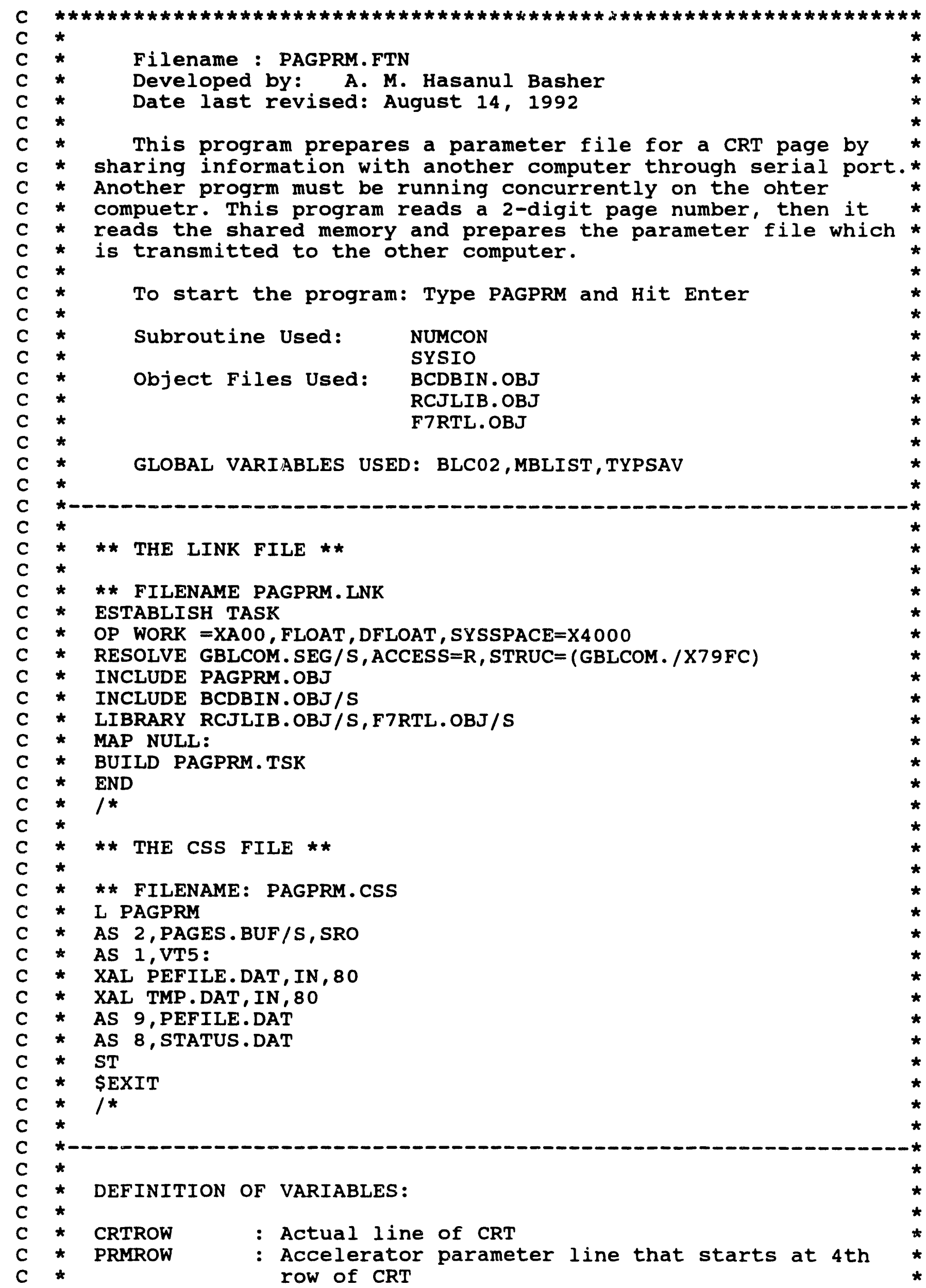


LINENO : Counts line number

BFPTR

BUFPTR

WDPTR

PRCPTR

RESULT

SAVWRD

STPTR

STWRD

BITPTR

STAT

: Same as BFPTR at word pointer.
: Buffer pointer obtained from POBUF(5, PRMROW)

: Word pointer obtained from buffer pointer. This * is used to locate the appropriate words required* to calculate parameter values.

: Pointer for words used to calculate the percent of parameter value.

: Parameter value calculated from words located *

: Percent of parameter value calculated from word * saved at location percent pointer.

: Status pointer for status word.

: Staus word that contains the status bit. The word is is located by status pointer.

: Bit pointer that carries the position of status * bit in status word.

: Value of status bit in status word.

The subroutine NUMCON does the numerical conversions. It needs* arguments such as BUFPTR, DFBUF (5, PRMROW), RESULT, * POBUF (6, PRMROW), and PERCENT and returns the value of RESULT * and PERCENT. From buffer pointer the routine determines the * word pointer and the type of data. With the word pointer it * also locates BLCO2 and MBLIST and calculate the RESULT and * PERCENT dependent on the type of data. The PERCENT value * indicates the percent of control setting. If data is inactive * RESULT is returned as INACTIVE. The routine uses different * mathematical formula for different types. The data types are * $0,1,2,3,4,6,7,8,9,10,18$, and 19 . It also calculates * values (RESULT) for negative pointer ( pointer $=-8$ or -9 ). The PERCENT is calculated only if data type is 0 and POBUF (6, PRMROW) is +ve.

COMMON /GBLCOM/ BLCO2, MBLIST, TYPSAV

COMMON /CRTPAGE/ABUF, POBUF, BITBUF, DFBUF

INTEGER* 4 ABUF $(16,32)$, LUPAGE, PBLK(5), STATUS, RANADD

INTEGER * $4 \operatorname{BLC02}(2,1024)$ ，TYPSAV $(2,1024)$ ，TYPE, SVDAT, STWRD

INTEGER 2 BFPTR, BUFPTR, WDPTR, PRCPTR, EXP, PRMROW, CRTROW

INTEGER *2 POBUF $(6,24), \operatorname{BITBUF}(8,24), \operatorname{DFBUF}(5,24)$

INTEGER * 2 STPTR, LOCATE, LBYTE, BITPTR, PAGNO

INTEGER $* 2$ COLOR (10), BITPTR1, LI (10), PBUF $(40,24)$

REAL MBLIST $(2,1024)$, EXPF, SVDATF, TMPRES

LOGICAL STAT

INTEGER *2 LINENO (10), LCOUNT, TOTC (27), NTOTC (27)

INTEGER $* 2$ A (10) , C, D (2) , L1, L2 , K, NC, PLACES, START, L, F (4) , G

INTEGER *2 ASSN, POINTER

INTEGER * 4 PBLK1 (5), PBLK2 (5), PBLK3 (5)

CHARACTER $* 9$ RESULT, PERCENT, SAVWRD

CHARACTER * 10 SAVFMT

CHARACTER $* 2$ PAGE, ANS, B, E

CHARACTER 1 RES, PER, SAV , COLR, AST, NUMB, READY

DATA LINENO/48,49,50,51,52,53,54,55,56,57/ 
$\operatorname{OPEN}(3$, FILE=' CON : ')

OPEN (5, FILE= ' CON : ')
; input from console

; output to console
C

C

C

C

C

C

C

C

C

999 READY $=$ '?'

950 CALL SYSIO (PBLK, $\left.Y^{\prime} 49^{\prime}, 1, F, 1,0\right)$

CALL ILBYTE $(G, F(1), 0)$

IF (G.EQ.Y'0024') GO TO 951

GO TO 950

951 CALL SYSIO(PBLK, Y' 29', 1, READY, 1, 0)

DO $10 \mathrm{I}=1,2$

CALL SYSIO(PBLK, Y' 49', 1, A, 1, 0)

CALL ILBYTE (D (I), A(1), 0)

CALL SYSIO (PBLK, Y' 29', 1 , READY , 1, 0)

10 CONTINUE

$B=\operatorname{CHAR}(D(1))$

$E=\operatorname{CHAR}(D(2))$

$\mathrm{L} 2=\operatorname{CTOI}(\mathrm{E}, \mathrm{K})$

$\mathrm{LI}=\operatorname{CTOI}(\mathrm{B}, \mathrm{K})$

PAGNO $=10 * \mathrm{~L} 1+\mathrm{L} 2$

C

C

C

C

C

C

C

C

C

C

C

C

C

C

C

C

C

C

C

C

C

C

C

C

C

C SYSIO ERRORS TO THE CONSOLE. ON WHICH TO PERFORM THE I/O. TRANSFER

RANADD $=$ PAGNO $* 12$

LUPAGE $=2$

CALL IOERR (PBLK, STATUS)

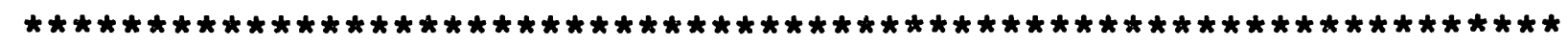

SYSIO SUBROUTINE PERFORMS I/O FUNCTIONS. IOERR ROUTINE REPORTS

LUPAGE - INTEGER 4 ARGUMENT THAT SPECIFIES THE LOGICAL UNIT

ABUF - STARTING ADDRESS OF THE BUFFER USED IN THE I/O

RANADD - AN INTEGER*4 ARGUMENT SPECIFYING THE LOGICAL RECORD NUMBER TO BE ACCESSED ON DATA TRANSFER REQUEST

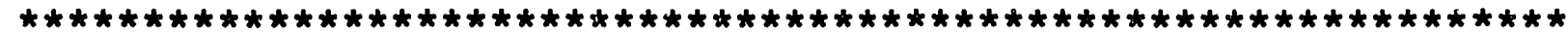

CALL SYSIO (PBLK, Y' 4D', LUPAGE, ABUF, 3328 , RANADD)

THIS PART OF THE PROGRAM SKIPS FIRST 3 CRT LINES. AFTER 3 LINES, IF IF BYTE 1 OF $\operatorname{ABUF}(1, L)$ IS NOT A DIGIT OR IF FIRST TWO BYTES OF ABUF $(1, L)$ ARE BLANKS NO NUMERICAL CONVERSION IS REQUIRED. OTHERWISE NUMCON SUBROUTINE IS CALLED. 
DO $940 \mathrm{KM}=1,27$

$\operatorname{TOTC}(\mathrm{KM})=0$

$\operatorname{NTOTC}(K M)=0$

940 CONTINUE

OPEN (9, FILE=' PEFILE. DAT' , STATUS='RENEW')

OPEN ( 8, FILE=' TMP.DAT' , STATUS='RENEW')

DO 100 CRTROW $=1.27$

ENCODE (RESULT, ' $(9 \mathrm{H}$

ENCODE ( PERCENT, ' $(9 \mathrm{H}$

ENCODE ( SAVWRD,' $(9 \mathrm{H}$

PRMROW = CRTROW -3

; find param. line no

303 CONTINUE

DO $303 I=1,16$

IF (ABUF (I,CRTROW).NE.' ') GO TO 304

GO TO 100

304 IF (CRTROW.LT.4) GO TO 100 ; line<4, do nothing

IF (IAND (ABUF ( 1, CRTROW) , Y'FFFF0000') . EQ.Y'20200000') GO TO 100

CALL ILBYTE (LB, ABUF $(1$, CRTROW) , 1) ; get byte 1

DO $301 I=1,10$

IF (LB.EQ.LINENO(I)) GO TO 302 ; byte 1 a digit?

301 CONTINUE

GO TO 100

302 BFPTR = POBUF (5, PRMROW)

BUFPTR $=$ POBUF $(5$, PRMROW $)$

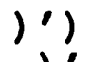

(1)

PRCPTR $=$ POBUF $(6$, PRMROW $)$

; buffer pointer

C
C
C
C
C
C
C
C
C
C

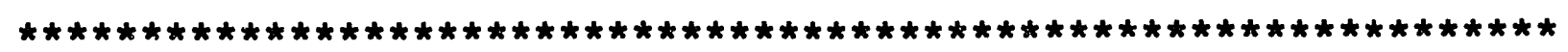

NUMCON SUBROUTINE IS CALLED FOR NUMERICAL CONVERSIONS

CALL NUMCON (BUFPTR, DFBUF ( 5 , PRMROW) , RESULT, POBUF ( 6 , PRMROW) , 1 PERCENT)

DETERMINE DATA TYPE TO CALCULATE PERCENT VALUE

IF (BFPTR) $119,119,103$

103 WDPTR $=$ BFPTR $/ 8+1$

i find word pointer

IF (BTEST (TYPSAV (1,WDPTR), 0)) GO TO 112 ; data active ?

GO TO 119

112 TYPE $=\operatorname{IAND}\left(\operatorname{ISHFT}(\operatorname{TYPSAV}(1, \operatorname{WDPTR}),-16), Y^{\prime} F F^{\prime}\right) ;$ data tYpe IF (TYPE.NE.0) GO TO 119

C

C

CALCULATE PERCENT VALUE FROM SAVED WORD

ENCODE ( SAVWRD,' (9H

IF (PRCPTR. LE. O) GO TO 119

PRCPTR = PRCPTR $/ 8+1$; get percent pointer

ASSN = ISHFT (IAND (TYPSAV $(2$, PRCPTR $\left.\left.), Y^{\prime} 80000000^{\prime}\right),-31\right)$

EXP $=$ ISHFT (IAND (TYPSAV (1, PRCPTR), Y'1F000000'), -24)

EXPF $=$ EXP

SVDAT = IAND (TYPSAV $(2$, PRCPTR), Y'7FFFF') $;$ get saved word

SVDATF $=$ SVDAT

TMPRES $=($ SVDATF $/ 2 \star \star$ EXPF $) * 100$

i float the word

SAVFMT $='(F 6.2)^{\prime}$

ENCODE (SAVWRD, SAVFMT) TMPRES

GO TO 119

; percent in right format

C 
C

C

C

C

C

C

C

C

$119 \mathrm{~K}=0$

DO $861 I=1,3,2$

IF (POBUF (I, PRMROW) . LE.0) GO TO 861

STPTR $=$ POBUF $(I$, PRMROW $) / 8+1$

IF (TYPSAV (1,STPTR) . GE.0) GO TO 861

DO $862 \mathrm{~J}=1,3,2$

$J J=2 *(I-1)+J$

IF (BITBUF (JJ, PRMROW) . EQ.0) GO TO 862

$K=K+1$

$\mathrm{LL}(\mathrm{K})=\mathrm{JJ}$

STWRD $=$ BLC02 $(2$, STPTR $)$

BITPTR = BITBUF (JJ, PRMROW $)$

BITPTR1 = BITPTR

IF (BITPTR . LT . O) THEN

BITPTR $=-$ BITPTR

ELSE

STWRD $=$ NOT $(S T W R D)$

ENDIF

STAT = BTEST (STWRD, BITPTR)

IF (STAT) THEN

ELSE

COLOR $(K)=\operatorname{IAND}\left(\right.$ DFBUF (K, PRMROW), $Y^{\prime}$ OOFF')

ENDIF

COLOR $(K)=$ ISHFT (IAND (DFBUF (K, PRMROW), $\left.Y^{\prime} F F 00^{\prime}\right),-8$ )

862 CONTINUE

C

861 CONTINUE

** PRINT PAGE INFORMATION **

$R$ - IF RESULT IS CALCULATED FOR A LINE THEN ' $R$ ' IS PRINTED IN THAT LINE AND THE RESULT VALUE

$P$ - IF PERCENT IS CALCULATED FOR A LINE THEN 'P' IS PRINTED IN THAT LINE AND THE PERCENT VALUE

$S$ - IF SAVWRD IS CALCULATED THEN ' $S$ ' IS PRINTED ALONG WITH IT'S VALUE

$K$ - IF STATUS FIELDS ARE PRESENT FOR A LINE THEN ' $K$ ' IS PRINTED WITH A VALUE INDICATING THE NUMBER OF LABELS

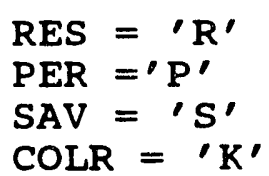

C
IF (RESULT . EQ.'
' AND. PERCENT . EQ.'
1 . AND. 
C

1 SAVWRD.EQ.'

C

C

C

C

C

C

c

C

C

C

C

c

(RESULT . NE.

IF (RESULT . EQ .'

1 SAVWRD.EQ.'

IF (RESULT . EQ.'

1 SAVWRD.NE.'

IF (RESULT . EQ . '

1 SAVWRD.NE.'

IF (RESULT . EQ.'

1 SAVWRD.EQ.'

IF (RESULT . EQ.'

1 SAVWRD. EQ.

IF (RESULT . EQ.'

1 SAVWRD.NE.'

IF (RESULT . EQ.'

1 SAVWRD.NE.

IF (RESULT . NE.'

1 SAVWRD.EQ.'

IF (RESULT . NE.'

1 SAVWRD.EQ.'

IF (RESULT . NE.'

1 SAVWRD.NE.'

IF (RESULT . NE.'

1 SAVWRD.NE.'

IF (RESULT . NE.'

1 SAVWRD.EQ.'

IF (RESULT . NE.'

1 SAVWRD. EQ.'

1 SAVWRD.NE.'

- AND. K.EQ.0) GO TO 100

, AND. PERCENT . EQ.'

, .AND.

, AND. K.NE.0) GO TO 1

- AND. PERCENT . EQ.'

- .AND. K.EQ.0) GO TO 2

' AND. PERCENT . EQ .'

- AND. K.NE.0) GO TO 3

' AND. PERCENT.NE.'

'. AND. K.EQ.0) GO TO 4

' AND. PERCENT.NE.'

- AND. K.NE.0) GO TO 5

' . AND. PERCENT . NE.'

- .AND. K.EQ.0) GO TO 6

- AND. PERCENT .NE.'

- AND. K.NE.0) GO TO 7

- . AND. PERCENT . EQ.'

, AND. K.EQ.0) GO TO 8

' .AND. PERCENT. EQ.'

- AND. K.NE.O) GO TO 9

- .AND. PERCENT . EQ.'

- AND. K.EQ.0) GO TO 20

, .AND. PERCENT . EQ.'

- AND. K.NE.0) GO TO 21

' AND. PERCENT.NE.'

- AND. K.EQ.0) GO TO 22

- .AND. PERCENT.NE.'

- AND. K.NE.0) GO TO 23

, AND. PERCENT.NE.'

'.AND. K.EQ.0) GO TO 24
, . AND.

. AND.

. AND.

. AND.

. AND.

. AND.

. AND.

, . AND.

, . AND.

. AND.

. AND.

. AND.

- AND.

C
C
C
C
C
C
C

\section{PRINT STARTS HERE **}

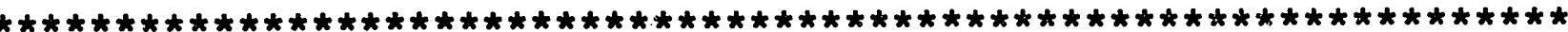

LCOUNT $=$ LCOUNT +1

TOTC (LCOUNT) $=36+4 * K$

WRITE $(8,47)$ PRMROW, RES, PER, SAV , COLR, ASSN , RESULT , PERCENT , SAVWRD,

$1 \quad K,(L L(L), L=1, K),(\operatorname{COLOR}(L), L=1, K)$

47 FORMAT (I2, A1, A1, A1, A1, I2, A9, A9, A9, I1, 8 (Z2))

GO TO 100

C

1 LCOUNT $=$ LCOUNT +1

$\operatorname{TOTC}($ LCOUNT) $=6+4 * \bar{K}$

WRITE $(8,44)$ PRMROW, COLR, ASSN , K, ( $L L(L), L=1, K),(\operatorname{COLOR}(L), L=1, K)$ 


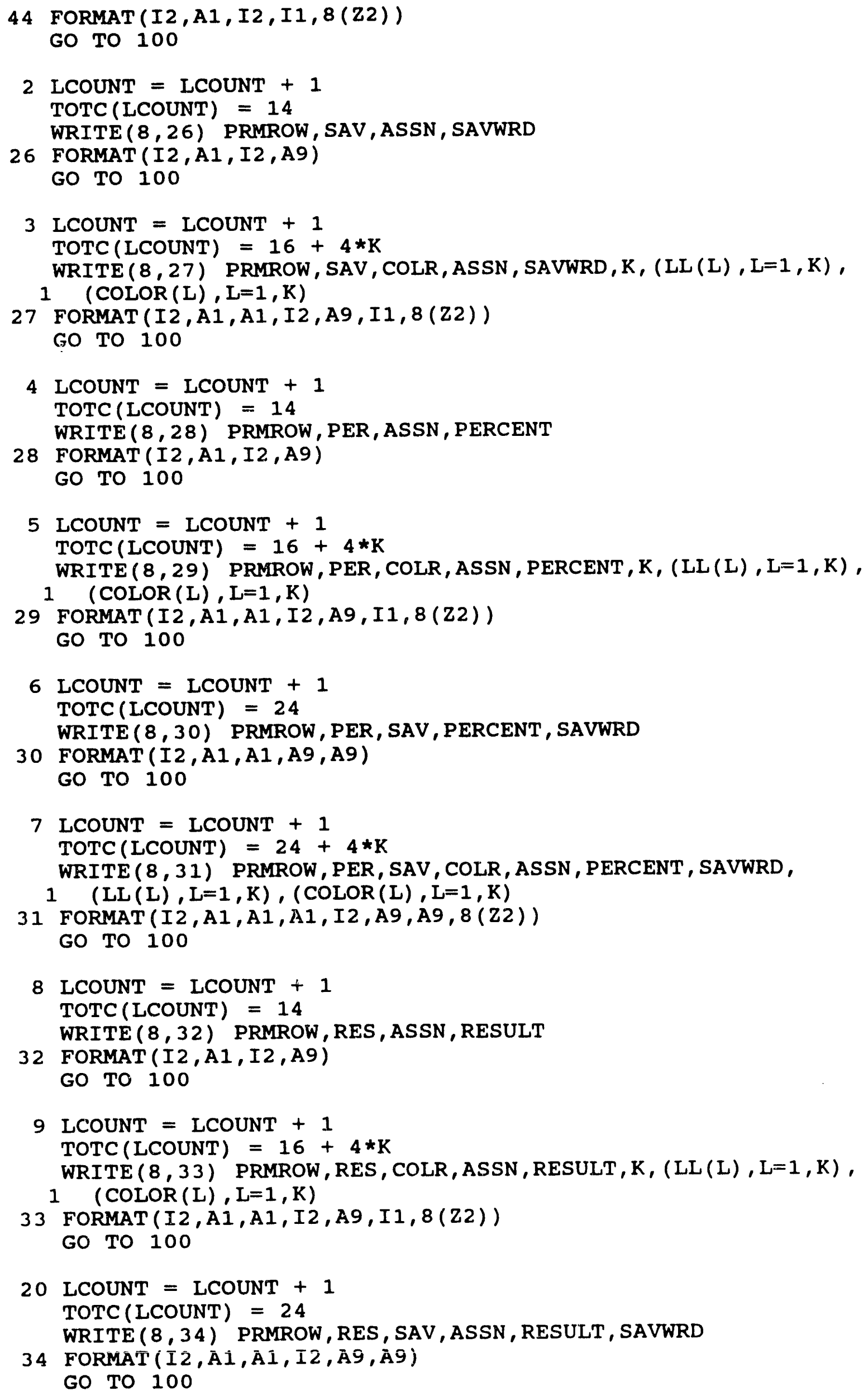


C

21 LCOUNT $=$ LCOUNT +1

TOTC $($ LCOUNT) $=26+4 * K$

WRITE $(8,35)$ PRMROW, RES, SAV , COLR, ASSN , RESULT , SAVWRD , K,

$1 \quad(L L(L), T,=1, K)$, ( COLOR (L) , L=1,K)

35 FORMAT (I2, A1, A1, A1, I2, A9, A9, I1, 8(Z2))

GO TO 100

C

22 LCOUNT $=$ LCOUNT +1

TOTC (LCOUNT) $=24$

WRITE $(8,36)$ PRMROW, RES, PER, ASSN, RESULT , PERCENT

36 FORMAT (I2, A1, A1, I2, A9, A9)

GO TO 100

C

23 LCOUNT $=$ LCOUNT +1

TOTC (LCOUNT) $=26+4 * K$

WRITE $(8,77)$ PRMROW, RES, PER, COLR, ASSN, RESULT , PERCENT, K,

$1 \quad(L L(L), L=1, K),(\operatorname{COLOR}(L), L=1, K)$

37 FORMAT (I2, A1, A1, A1, I2, A9, A9, I1, $8(\mathrm{Z2})$ )

C

GO TO 100

24 LCOUNT $=$ LCOUNT +1

TOTC (LCOUNT) $=34$

WRITE ( 8,38$)$ PRMROW, RES, PER, SAV , ASSN , RESULT , PERCENT, SAVWRD

C

38 FORMAT (I2, A1, A1, A1, I2, A9, A9, A9)

100 CONTINUE

C

C

C

C

c

IF LCOUNT IS 0 , NO FILE IS PREPARED, SO SEND NO-FILE SIGNAL ('\#')

IF NOT, ARRANGE THE FILE IN RIGHT FORMAT

C

C

IF (LCOUNT.EQ.0) GO TO 910

DO $39 I=1$, LCOUNT

$\operatorname{NTOTC}(I+1)=\operatorname{TOTC}(I)$

39 CONTINUE

NTOTC $(1)=$ LCOUNT

WRITE $(9,40)$ (NTOTC (N) , N=1, LCOUNT+1)

40 FORMAT ( $40(12)$ )

CLOSE (8)

OPEN ( $8, F I L E=$ 'TMP.DAT')

$\mathrm{L}=\operatorname{NTOTC}(1)$

DO $42 \mathrm{~J}=1, \mathrm{~L}$

$N C=N \operatorname{rOTC}(\mathrm{J}+1) / 2$

$\operatorname{READ}(8,43, \operatorname{END}=81) \quad(\operatorname{PBUF}(I, J), I=1, N C)$

WRITE $(9,43) \quad$ (PBUF $(I, J), I=1, N C)$

43 FORMAT ( $40(A 2))$

42 CONTINUE

C

C

81 CLOSE (9)

OPEN (9, FILE='PEFILE. DAT')

$I=\operatorname{NTOTC}(1)+1$

Do soo $J=1, L$

$\mathrm{NC}=\mathrm{L}$

IF (J.EQ.1) GO TO 901

$\mathrm{NC}=\operatorname{NTOTC}(\mathrm{J}) / 2$ 


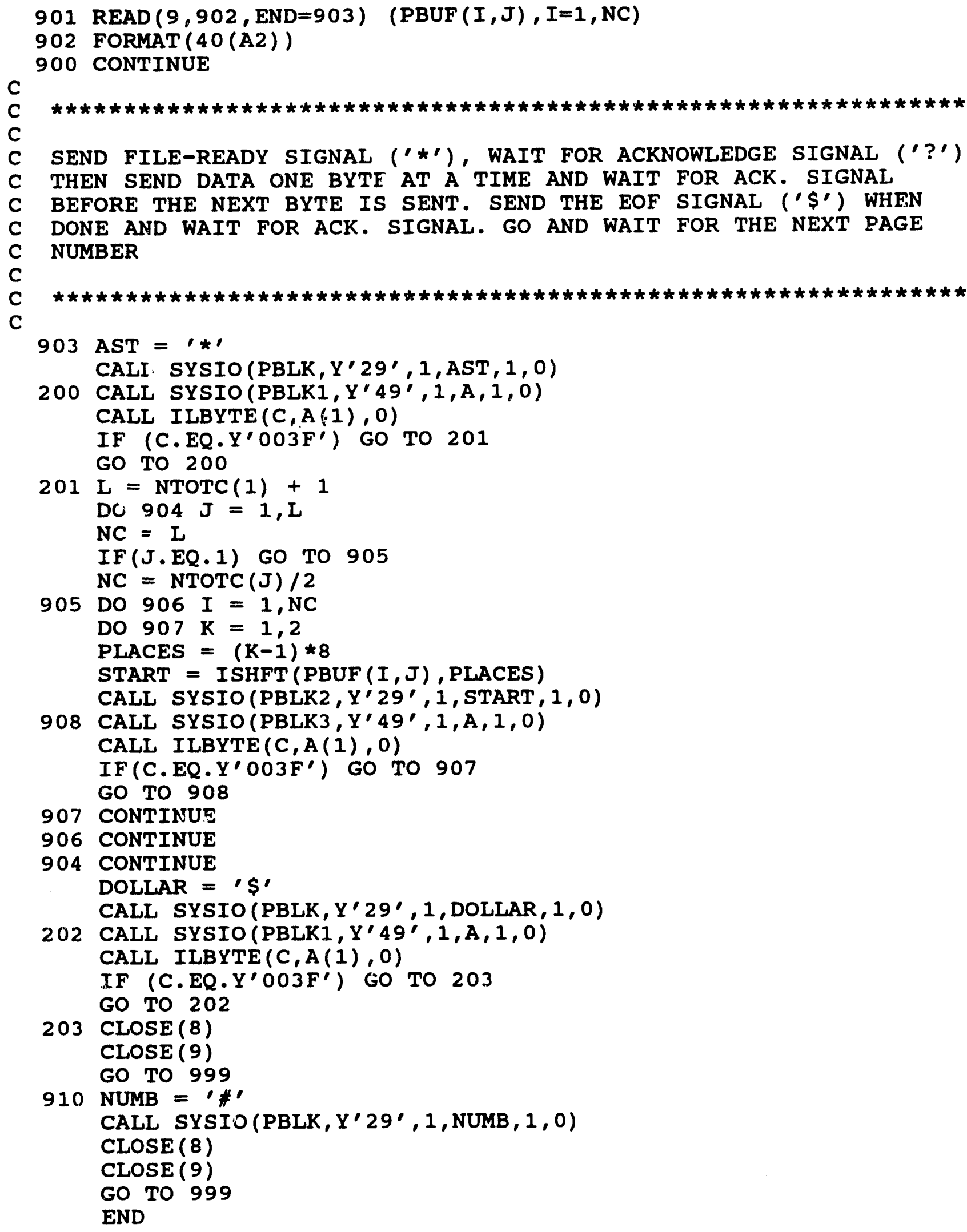



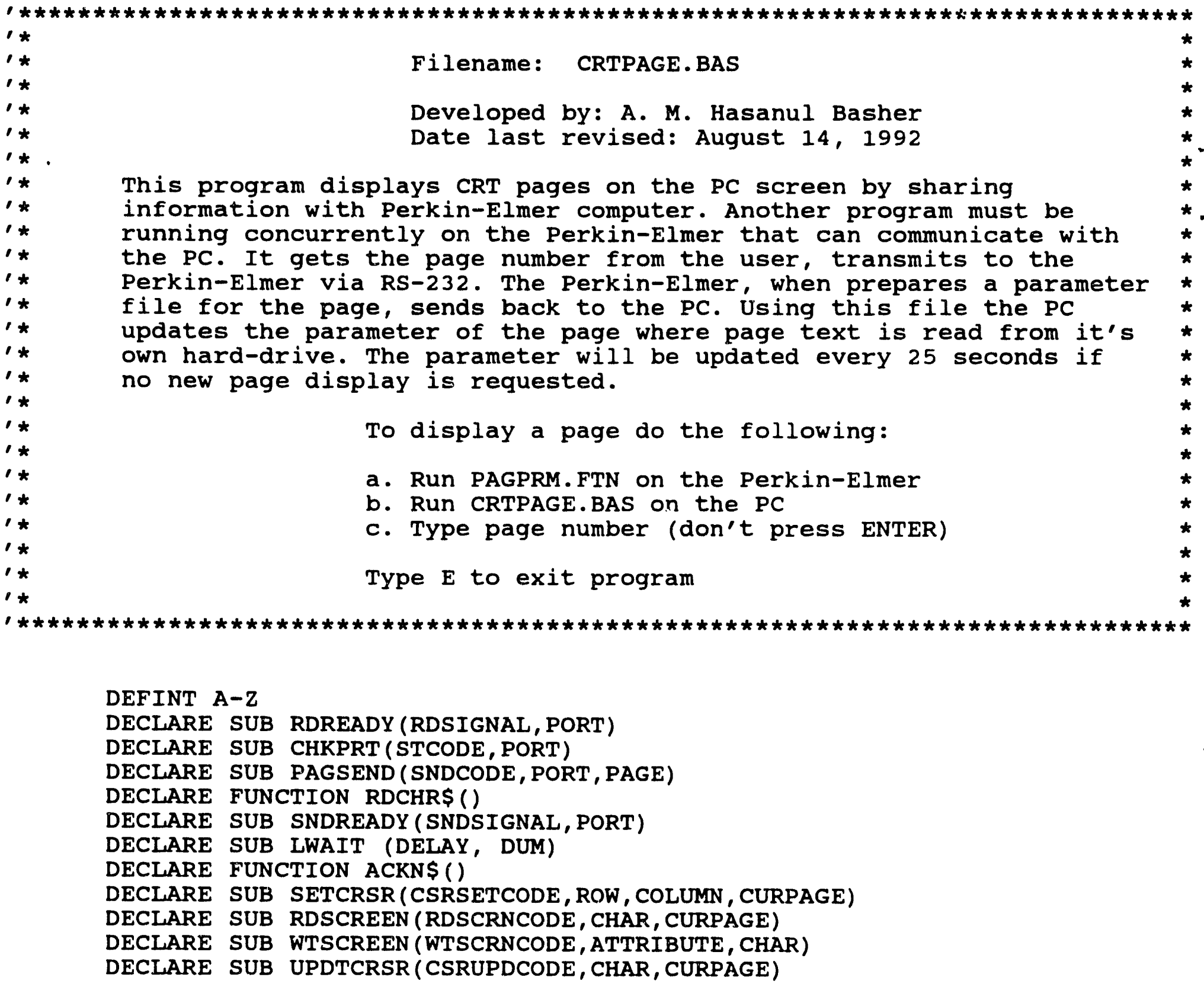
- Variable initialization
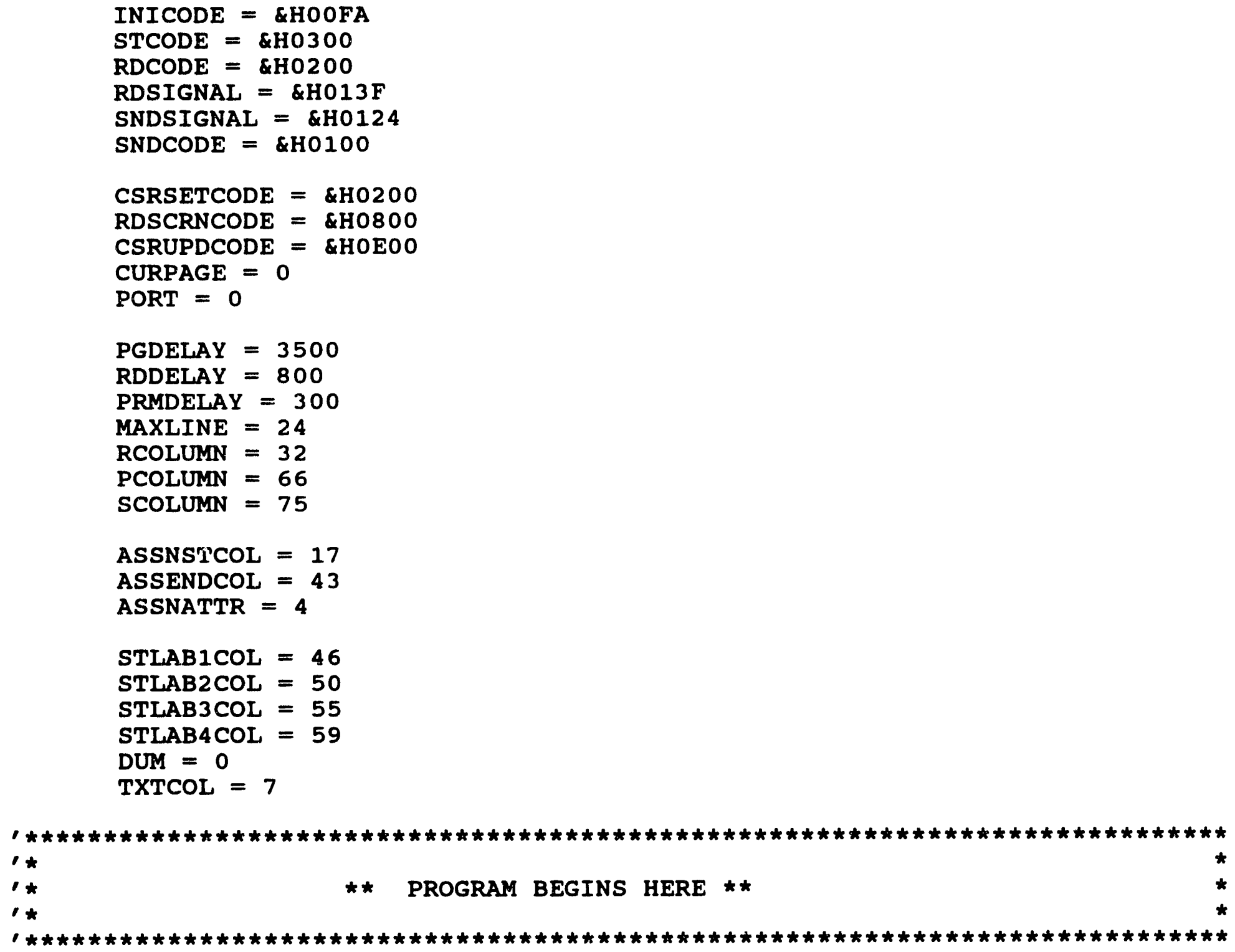

'Clear the screen, set screen color, 7 for white, 2 for green

CLS

COLOR TXTCOL, 0,3

'Initialize port. $A H$ is 00 and $A L$ has the initialization data,

' and DX has the port number. Port is initialized for 9600

'baud rate, even parity, 1 stop bit and 7-bit word.

INREGS.AX = INICODE

INREGS.DX $=$ PORT

CALL INTERRUPT ( \&H14, INREGS, OUTREGS)

'First time get the page number

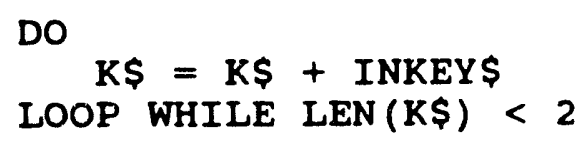


$\mathrm{QS}=\mathrm{K} \$$

ICHECK $=0$

GOSUB DISPPAGE

$\mathrm{KS}=" "$

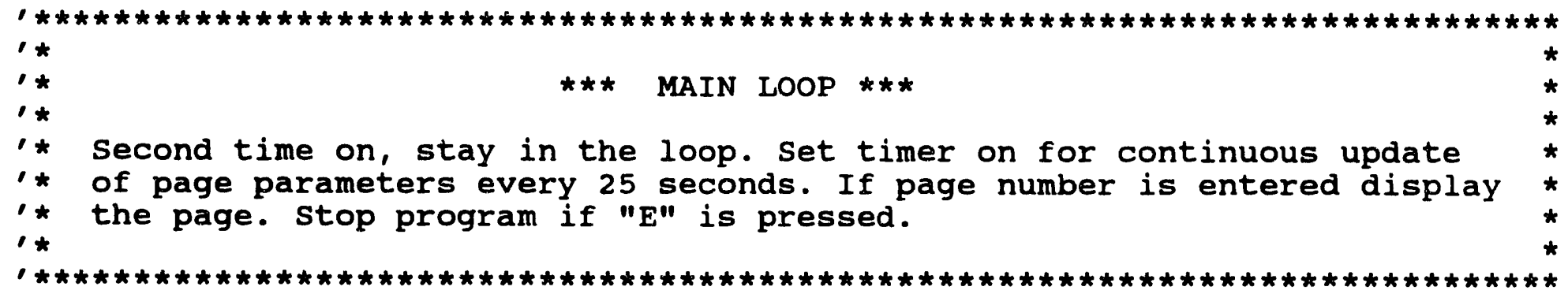

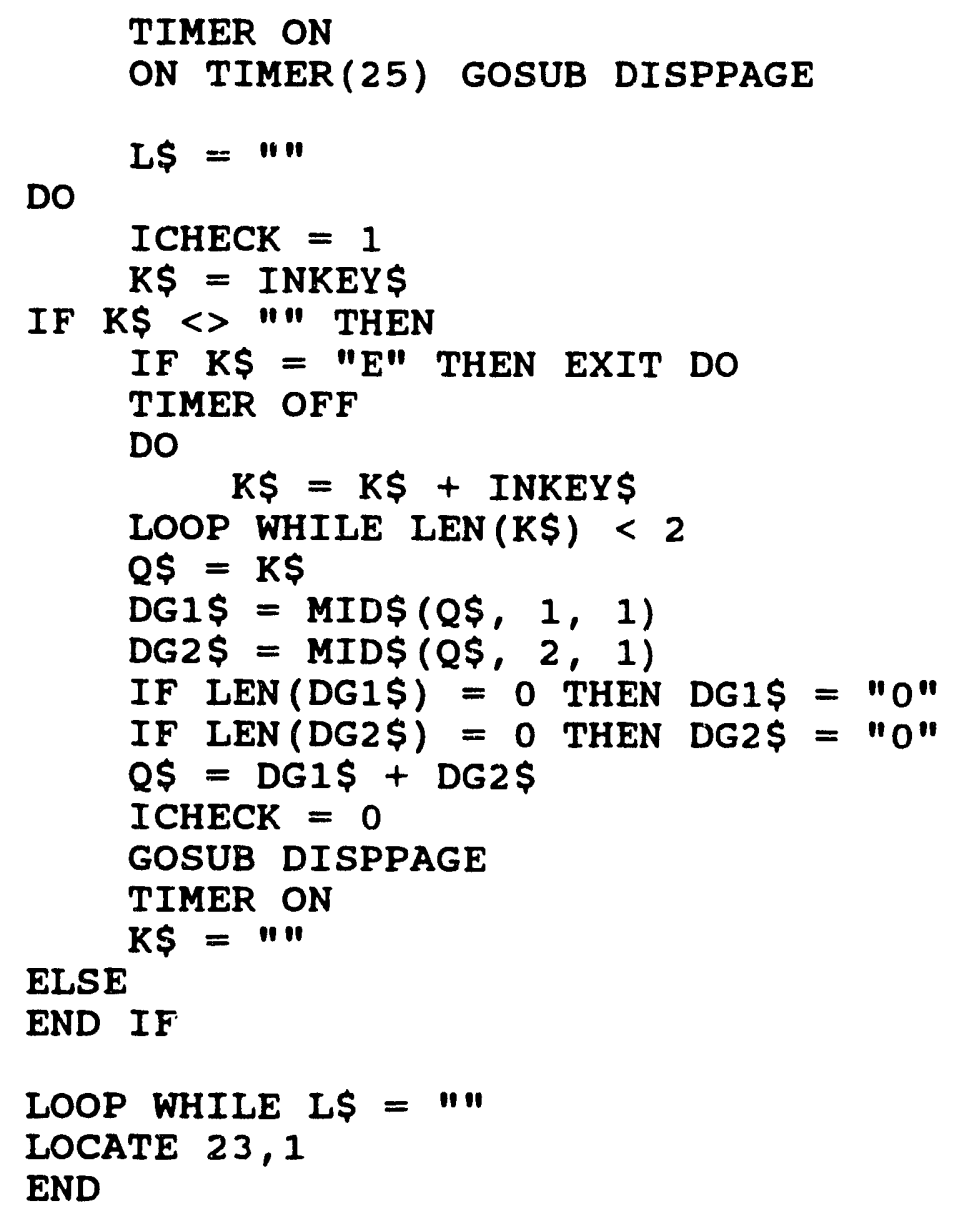

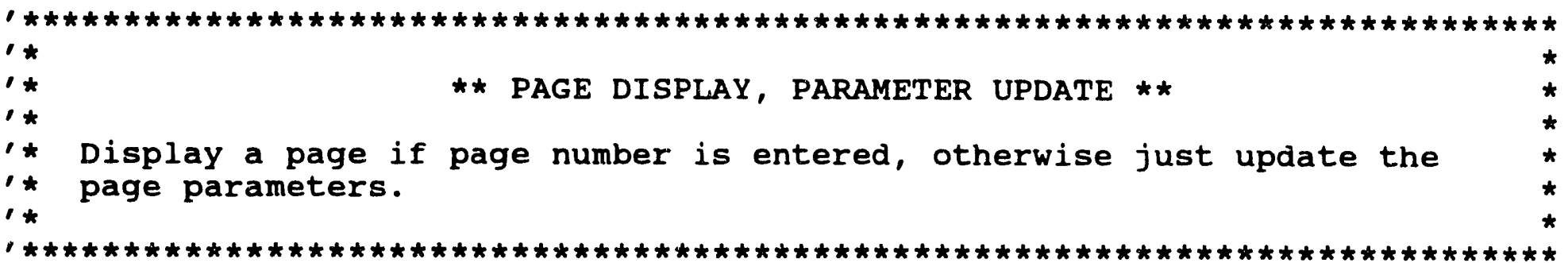

DISPPAGE :

GOSUB SNDPAGNO

GOSUB FLREADY

IF $C \$=" \# "$ THEN 


\begin{tabular}{|c|c|c|}
\hline & GOSUB & $\begin{array}{l}\text { GETPAGTEXT } \\
\text { DISPLTEXT }\end{array}$ \\
\hline ELS & GOSUB & DISPLIEXI \\
\hline & GOSUB & GETPARM \\
\hline & GOSUB & MKPRMFL \\
\hline IF & $\begin{array}{l}\text { ICHECK } \\
\text { CLS }\end{array}$ & $=0$ THEN \\
\hline & GOSUB & GETPAGTEXT \\
\hline & GosUB & DISPLTEXT \\
\hline ELS & & \\
\hline ENI & IF & \\
\hline & GOSUB & PRMTYPES \\
\hline & GOSUB & UPDTPRM \\
\hline & GOSUB & STCOLOR \\
\hline & GOSUB & ASSIGN \\
\hline ENI & IF & \\
\hline
\end{tabular}

RETURN

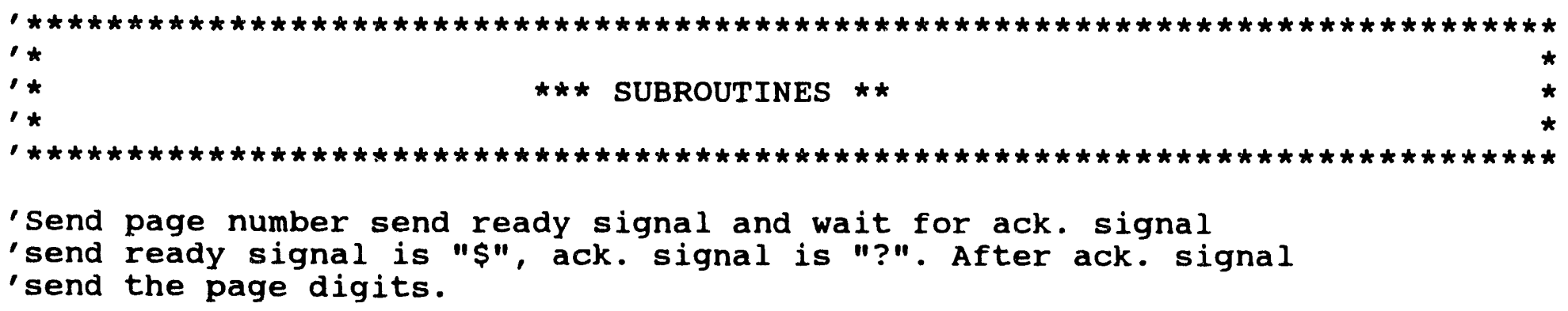

SNDPAGNO:

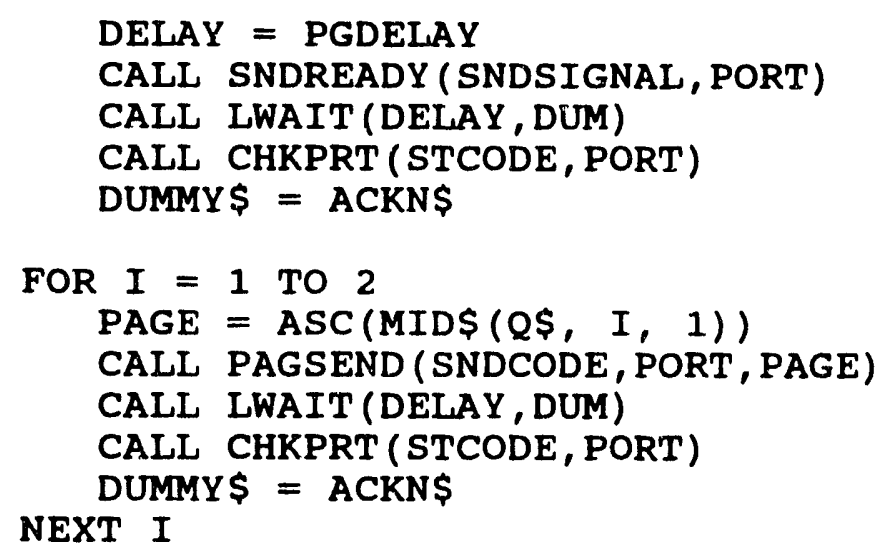

\section{RETURN}

'Wait for parameter file ready signal ("*") from Perkin-Elmer. No file

' is prepared if signal recvd. is "\#". If file ready, read the file.

FLREADY :

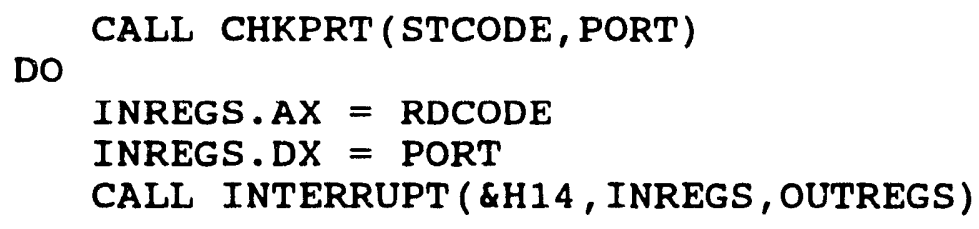


C\$ = CHR\$ (OUTREGS.AX AND \&H7F)

IF $C \$=" \# "$ THEN EXIT DO

LOOP WHILE C\$ $<>" * "$

\section{RETURN}

'Get the parameters of the file from Perkin-Elmer. Send read-ready signal,

'then read a character followed by sending ack. signal after each

'character read. Read-ready and ack. signal are both "?".

GETPARM :

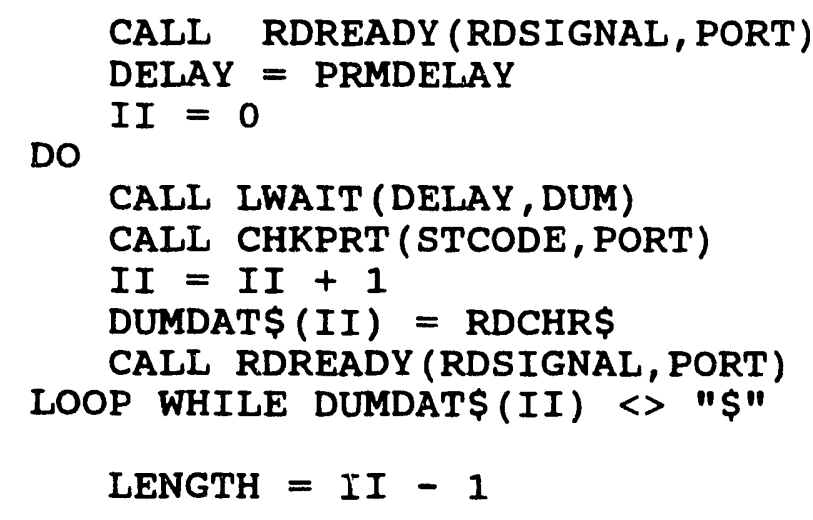

RETURN

'After receiving data from Perkin-Elmer, prepare similar file. Discard

'undesired characters that may be coming from the other side.

' Characters we need are all in CHECK\$.

MKPRMFL:

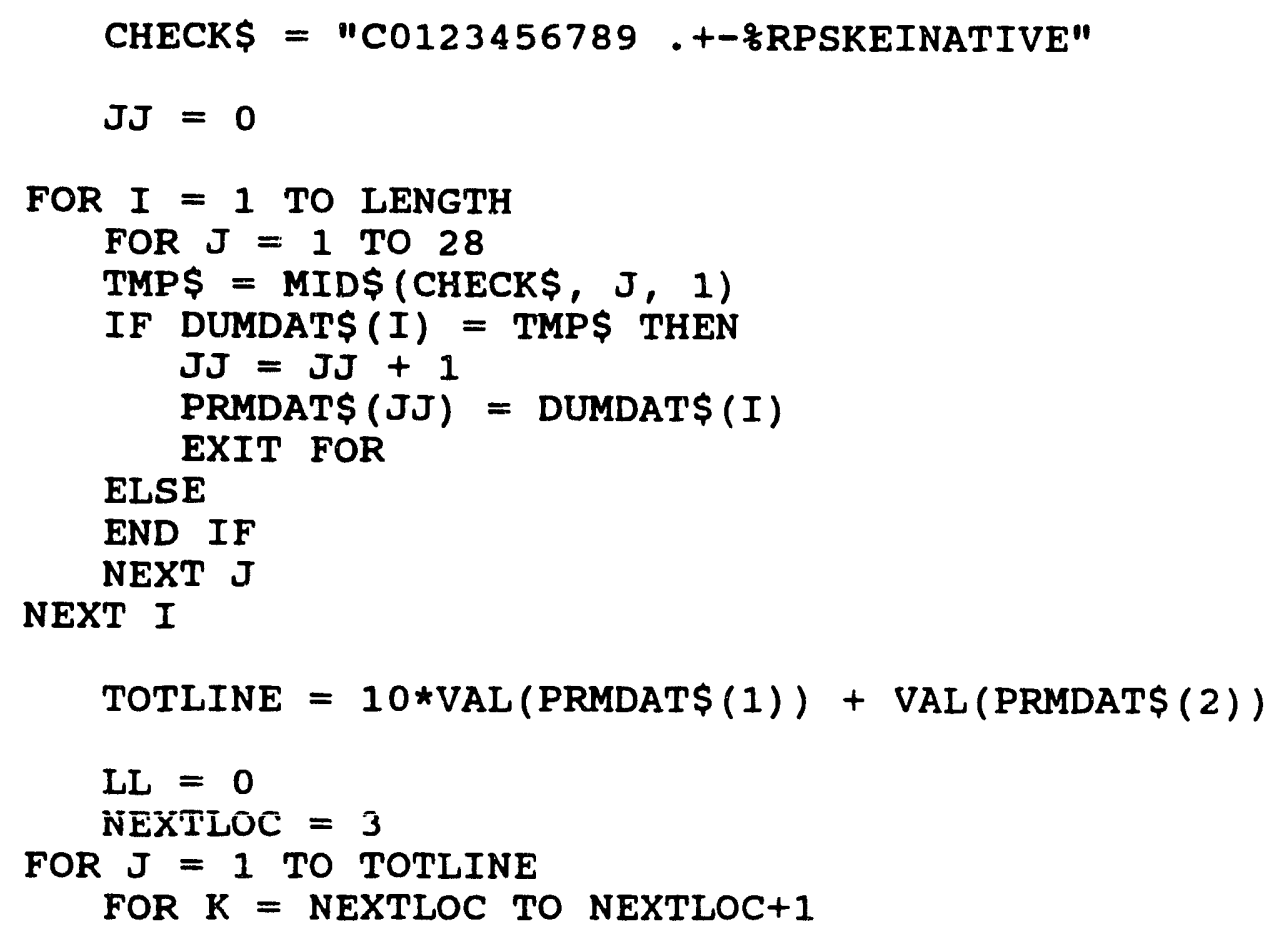


$L L=L L+1$

NOCHR\$ $(L L)=$ PRMDAT\$ $(K)$

NEXT $K$

NEXTLOC $=$ NEXTLOC +2

$\operatorname{TOTCHR}(J)=10 * \operatorname{VAL}(\operatorname{NOCHR}(1))+\operatorname{VAL}(\operatorname{NOCHR} \$(2))$

NEXT J

$L L=0$

'Prepare the file of parameters here.

OPEN "PEFILE.DAT" FOR OUTPUT AS \#2

FOR II $=1$ TO TOTLINE

LINECHR $=$ TOTCHR (II)

LINEND $=$ NEXTLOC + LINECHR -1

FOR JJ $=$ NEXTLOC TO LINEND

NEXT

PRINT \#2, PRMDAT\$(JJ);

NEXT

NEXTLOC $=$ LINEND +1

CLOSE \#2

'Rearrange the file by discarding the blank lines

$I=0$

OPEN "PEFILE.DAT" FOR INPUT AS \#2

DO UNTIL EOF (2)

$I=I+1$

LINE INPUT \#2, B\$(I)

LOOP

LINE INPUT \#2, P\$

CLOSE \#2

OPEN "PEFILE.DAT" FOR OUTPUT AS \#2

FOR $\mathrm{K}=1$ TO $\mathrm{I}$

NEXT

PRINT \#2, B\$(K)

CLOSE \#2

RETURN

'Locate the position at the beginning of the page, read 23 lines

'from there.

GETPAGTEXT:

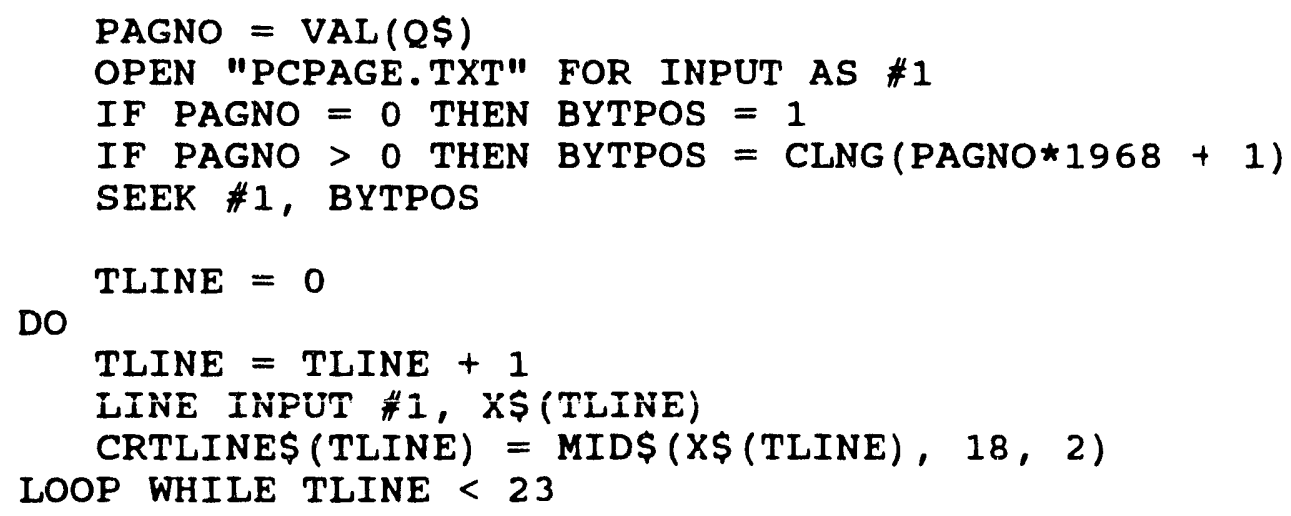




\section{RETURN}

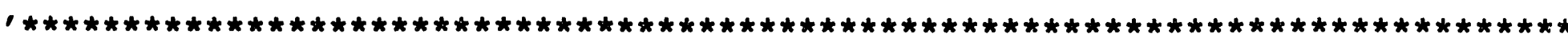

'Find types of parameters and number of parameters in each line

PRMTYPES :

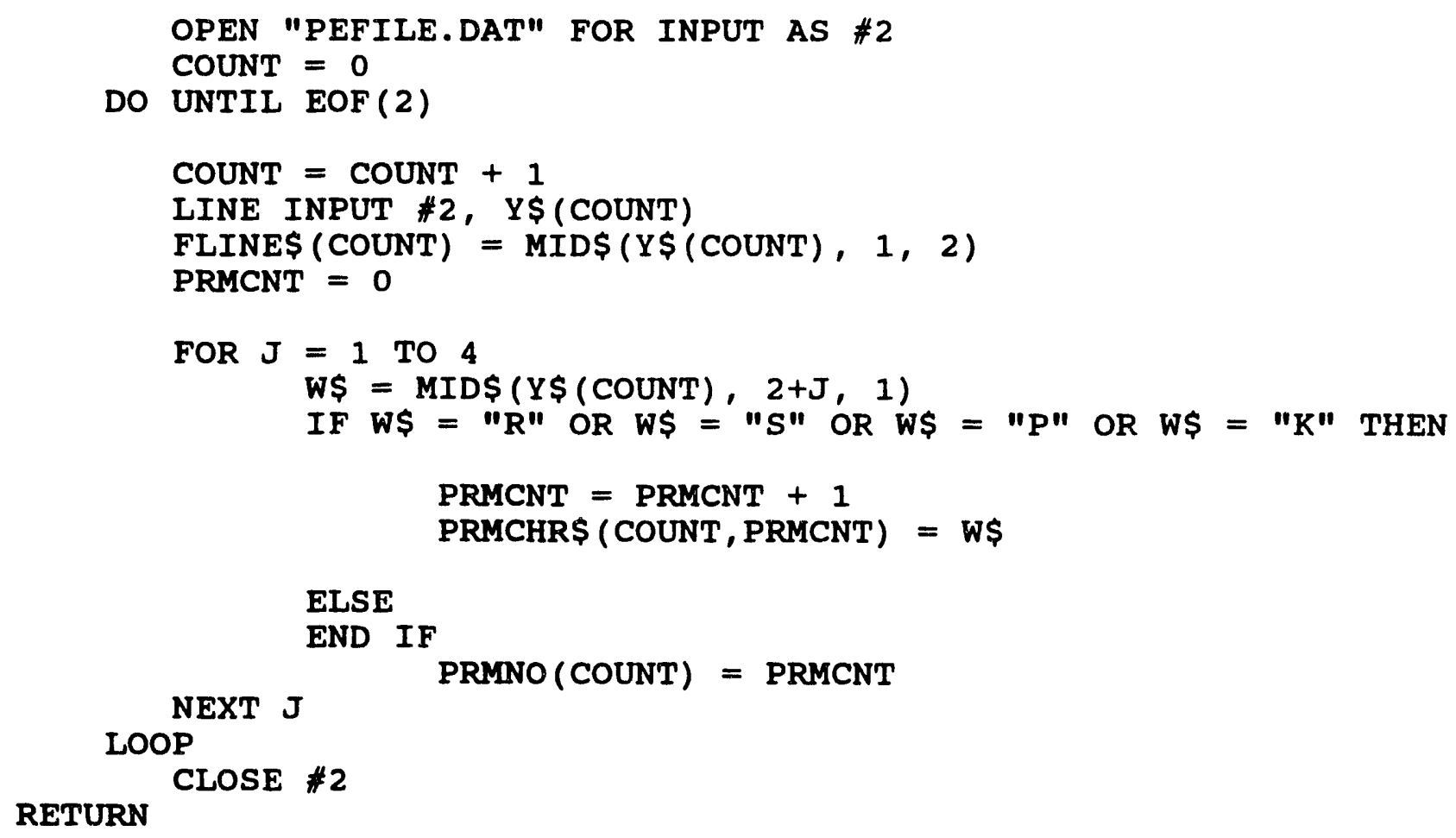

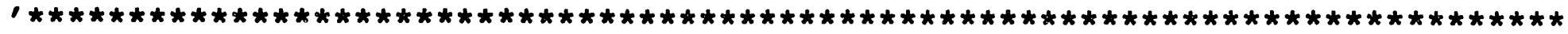

'Update parameter values and/or colors on the screen. Find CRT line 'number, check parameter type, set column location, print new values ' and/or colors.

UPDTPRM :

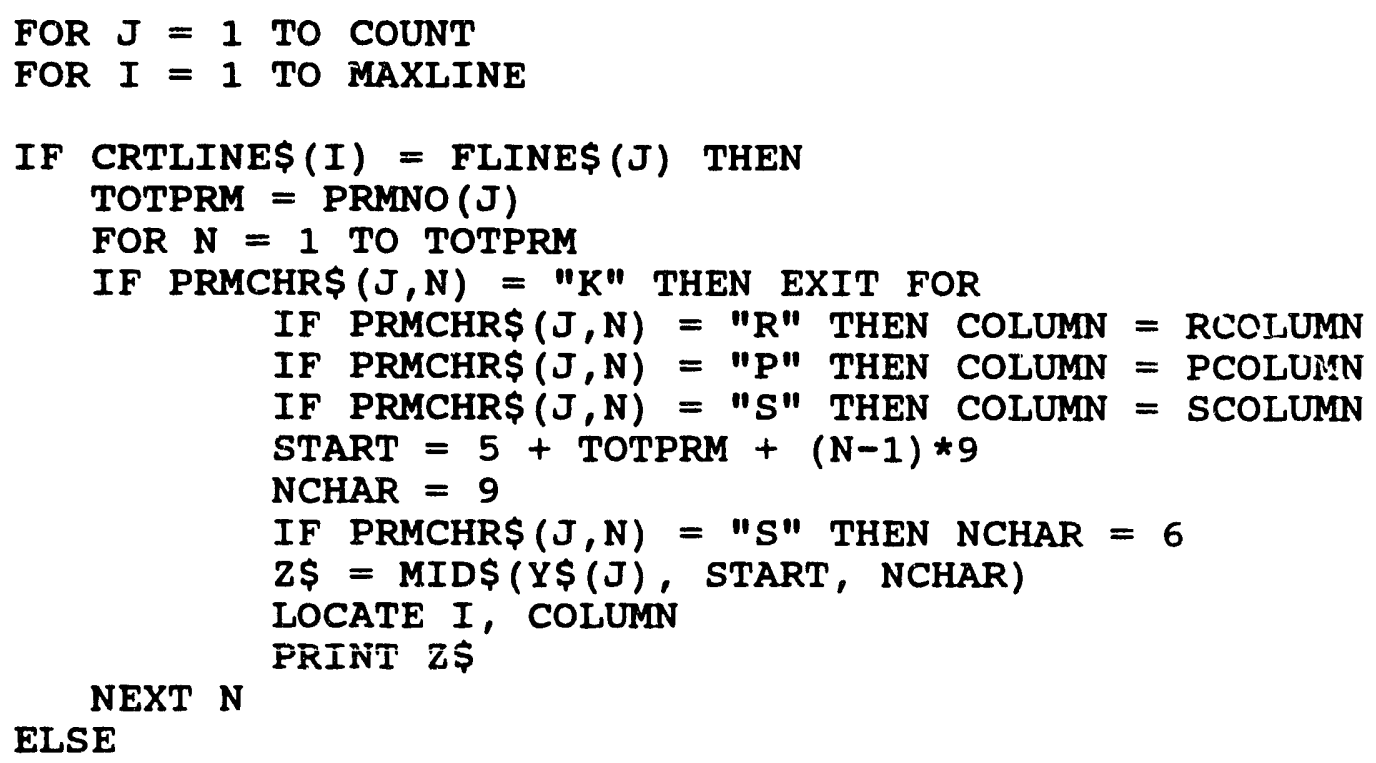


END IF

NEXT I

NEXT J

RETURN

'Check if a function is assigned, display in color if assigned.

ASSIGN :

FOR $\mathrm{J}=1$ TO COUNT

FOR $I=1$ TO MAXLINE

ROW $=I-1$

COLUMN $=$ ASSNSTCOL

ENDCOL = ASSENDCOL

ATTRIBUTE = ASSNATTR

TOTPRM $=$ PRMNO $(\mathrm{J})$

ASSNLOC $=4+$ TOTPRM

ASSGN\$ = MID\$ (Y\$(J), ASSNLOC, 1)

IF CRTLINE\$(I) = FLINE\$(J) THEN

IF ASSGN\$ = " 1 " THEN

CALL SETCRSR (CSRSETCODE, ROW, COLUMN, CURPAGE)

FOR JJ = COLUMN TO ENDCOL

CALL RDSCREEN (RDSCRNCODE, CHAR, CURPAGE)

CALL WTSCREEN (WTSCRNCODE, ATTRIBUTE, CHAR)

CALL UPDTCRSR (CSRUPDCODE, CHAR, CURPAGE)

NEXT JJ

ELSE

END IF

ELSE

END IF

NEXT I

NEXT J

RETURN

'Update Status Fields' Labels' colors. Find CRT line number, locate

' label column, find the color code and display in color.

STCOLOR:

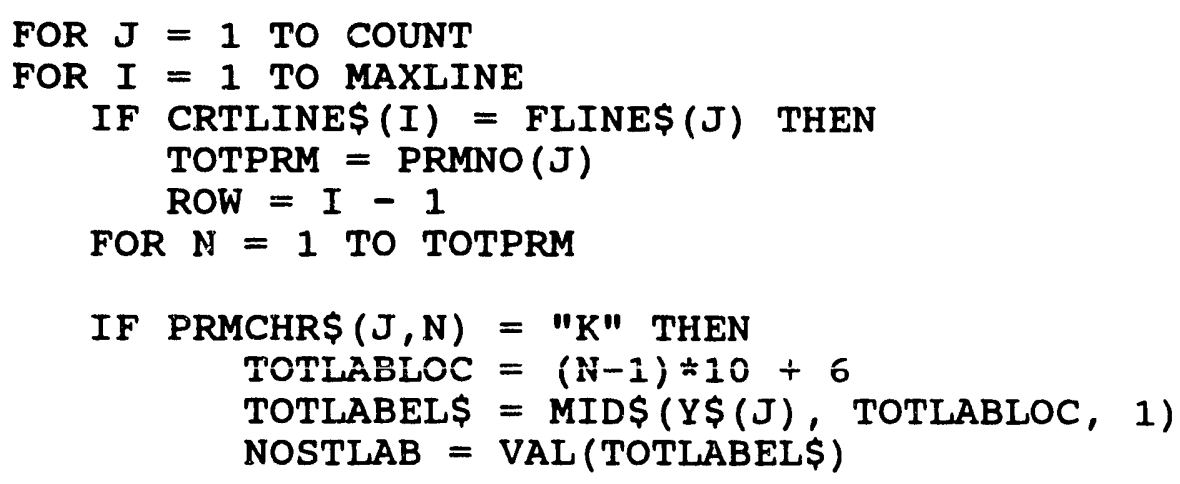


' $L A B N O L O C=$ TOTLABLOC +2

LABCOLLOC $=(\mathrm{N}-1) * 10+7+2 *$ NOSTLAB

FOR $M=1$ TO NOSTLAB

ILABELNO\$ = MID\$(Y\$(J), LABNOLOC, 1)
BGCOLOR\$ = MID\$(Y\$(J), LABCOLLOC, 1)
FGCOLOR\$ = MID\$(Y\$(J), LABCOLLOC+1, 1)
LABEL = VAL (LABELNO\$)

IF FGCOLOR\$ = "C" THEN

ELSE

$F G=8+6$

FG $=$ VAL (FGCOLOR\$) I 2

IF FG $=2$ THEN FG $=$ TXTCOL

END IF

$B G=\operatorname{VAL}(B G C O L O R \$)$

ATTRIBUTE $=((B G * 16)$ AND \&H70) OR (FG AND \&HF)

IF $F G<>0$ THEN

IF LABEL $=1$ THEN COLUMN = STLAB1COL

IF LABEL $=3$ THEN COLUMN = STLAB2COL

IF LABEL $=5$ THEN COLUMN = STLAB3COL

IF LABEL $=7$ THEN COLUMN $=$ STLAB4COL

CALL SETCRSR (CSRSETCODE, ROW, COLUMN, CURPAGE)

FOR II $=$ COLUMN TO COLUMN +2

CALL RDSCREEN (RDSCRNCODE, CHAR, CURPAGE)

CALL WTSCREEN (WTSCRNCODE, ATTRIBUTE, CHAR)

CALL UPDTCRSR (CSRUPDCODE, CHAR, CURPAGE)

NEXT II

ELSE

END IF

LABNOLOC $=$ LABNOLOC +2

NEXT M

LABCOLLOC $=$ LABCOLLOC +2

ELSE

END IF

NEXT N

ELSE

END IF

NEXT I

NEXT J

RETURN

'Display the texts of the page

DISPLTEXT:

FOR $I=1$ TO TLINE

NEXT

PRINT XS(I) 
RETURN

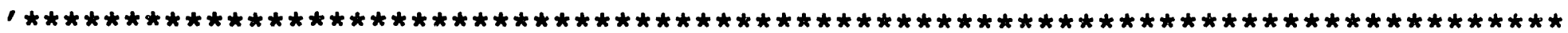

'RDREADY sunroutine writes the character "?" to the serial port com1,

'the write is success if bit-7 of $\mathrm{AH}$ register is 0 . "?" is the

'read-ready and the acknoledge signal. FUNCTION $01 \mathrm{H}$ is used on INT

'function call with $01 \mathrm{H}$ in $\mathrm{AH}$ and $3 \mathrm{FH}$ in $\mathrm{AL}$ register.

SUB RDREADY (RDSIGNAL, PORT)

DO

INREGS.AX = RDSIGNAL

INREGS.DX $=$ PORT

CALI INTERRUPT ( $\&$ H 14 , INREGS, OUTREGS)

END SUB

LOOP WHILE (OUTREGS.AX AND \&H8000) $<0$

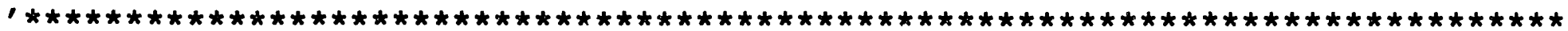

'Send page number ready signal("\$") to Perkin-Elmer. Wait until

'successful

SUB SNDREADY ( SNDSIGNAL, PORT)

DO

INREGS.AX = SNDSIGNAL

INREGS.DX = PORT

CALL INTERRUPT ( $\&$ H 14 , INREGS, OUTREGS)

END SUB

LOOP WHILE (OUTREGS.AX AND \&H8000) $<>0$

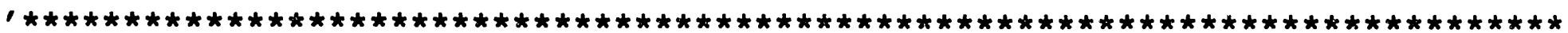

' Check port status, wait until data ready. If bito of $A H$ is 0 , data

' is not ready. Function $03 \mathrm{H}$ is used on INT function call.

SUB CHKPRT (STCODE, PORT)

Do

INREGS.AX $=$ STCODE

INREGS.DX $=$ PORT

CALL INTERRUPT ( $\&$ H 14 , INREGS, OUTREGS)

END SUB

LOOP WHILE (OUTREGS.AX AND 256) $=0$

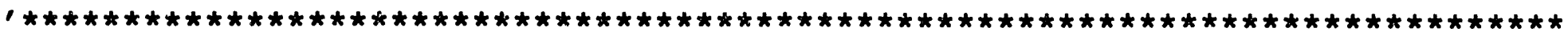

'Send page number to the port. Writes a character to serial port.

' FUNCTION $01 \mathrm{H}$ is used on INT function call with $01 \mathrm{H}$ in $\mathrm{AH}$ and

'page character to send in AL register.

SUB PAGSEND (SNDCODE, PORT, PAGE)

DO

INREGS.AX = SNDCODE + PAGE

INREGS.DX = PORT

CALL INTERRUPT ( $\&$ H 14 , INREGS, OUTREGS)

END SUB

LOOP WHILE (OUTREGS. AX AND \&H8000) $<>0$ 
'Wait loop

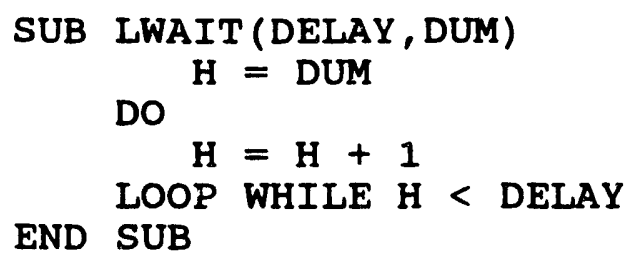

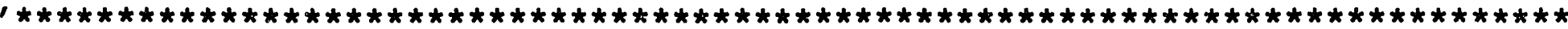

'Read character from serial port. FUNCTION $02 \mathrm{H}$ is used on INT

- function call with $02 \mathrm{H}$ in $\mathrm{AH}$. The character read from the port

' is returned in $A L$. Strip off the parity bit.

FUNCTION RDCHR\$

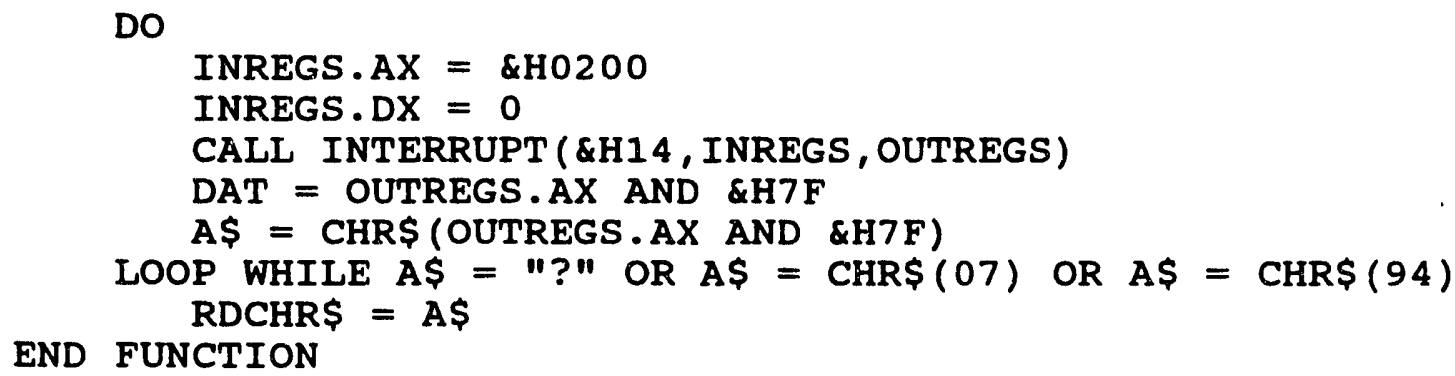

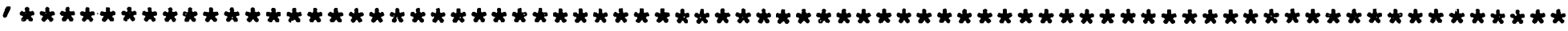

'Read acknowledge signal ("?") from Perkin-Elmer, wait until read.

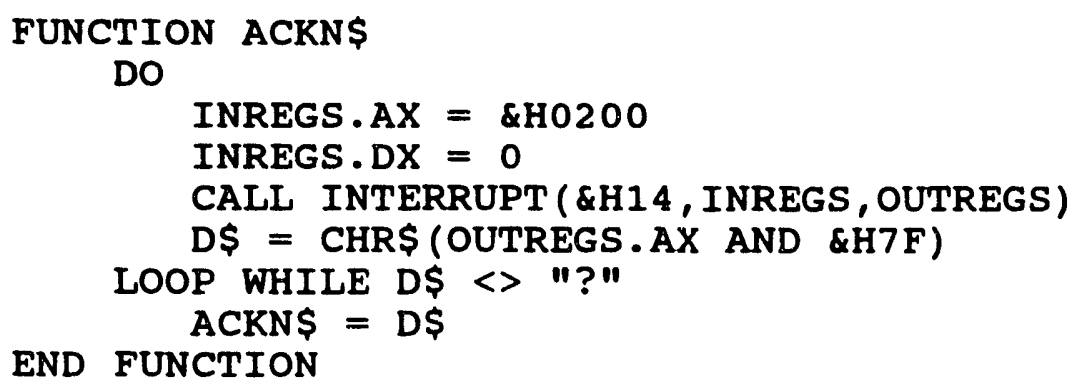

'set cursor position on the screen, in correct row and column for

'the current page

SUB SETCRSR (CSRSETCODE, ROW, COLUMN, CURPAGE)

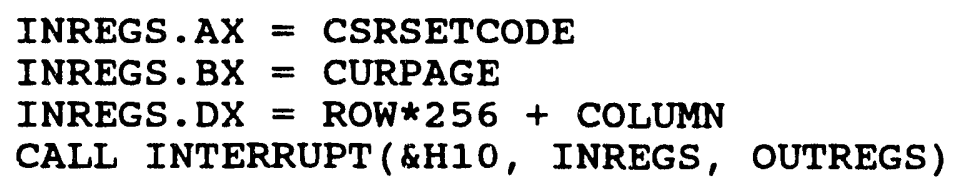

END SUB

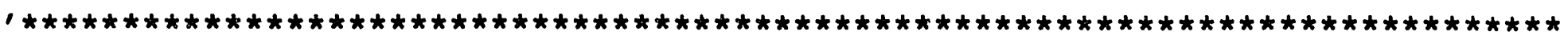

'read character at the cursor. Character is retured in AL register. 
SUB RDSCREEN (RDSCRNCODE, CHAR, CURPAGE)

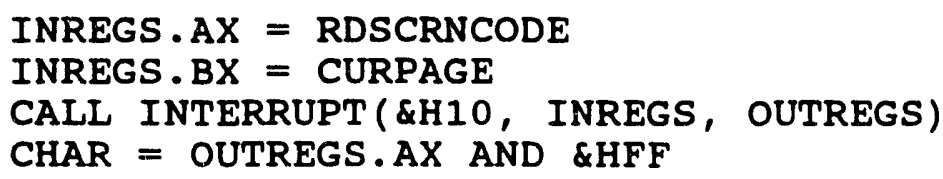

END SUB

'write character and attribute at cursor. Color attribute in BX and

' character in $\mathrm{AL}$ register.

SUB WTSCREEN (WTSCRNCODE, ATTRIBUTE, CHAR)

INREGS.AX $=\& H 0900+$ CHAR

INREGS.BX = ATTRIBUTE

INREGS. CX $=1$

CALL INTERRUPT ( $\&$ H10， INREGS， OUTREGS)

END SUB

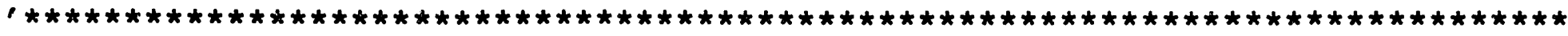

'update cursor position after a character is written

SUB UPDTCRSR (CSRUPDCODE, CHAR, CURPAGE)

INREGS.AX $=$ CSRUPDCODE + CHAR

INREGS.BX $=$ CURPAGE

CALI INTERRUPT (\&H10， INREGS， OUTREGS)

END SUB
} 


\section{INTERNAL DISTRIBUTION}

1. Cent:al Research Library

2. Document Reference

3-4. Laboratory Records

5. Laboratory Records, R.C.

6. ORNL Patent Office

7. $Y-12$ Technical Library

8. G. D. Alton

9. J. B. Ball

10. F. E. Bertrand

11. D. T. Dowling

12. D. L. Haynes

13. C. M. Jones

14. R. C. Juras

15. S. N. Lane

16. M. J. Meigs

17. G. D. Mills

18-20. S. W. Mosko

21. D. K. Olsen

22. B. A. Tatum

\section{EXTERNAL DISTRIBUTION}

23. Dr. A. M. Hasanul Basher, School of Engineering Technology, South Carolina State College, Orangeburg, SC 29117

24. J. T. Crockett, Jr., Director, Faculty and HBCU Programs, ORAU, Energy Bldg., Room OB-9, Oak Ridge, Tennessee 37831

25. Assistant Manager, Energy Research and Development, DOE/ORO

26-27. Office of Scientific and Technical Information, P. O. Box 62, Oak Ridge, TN 37831 

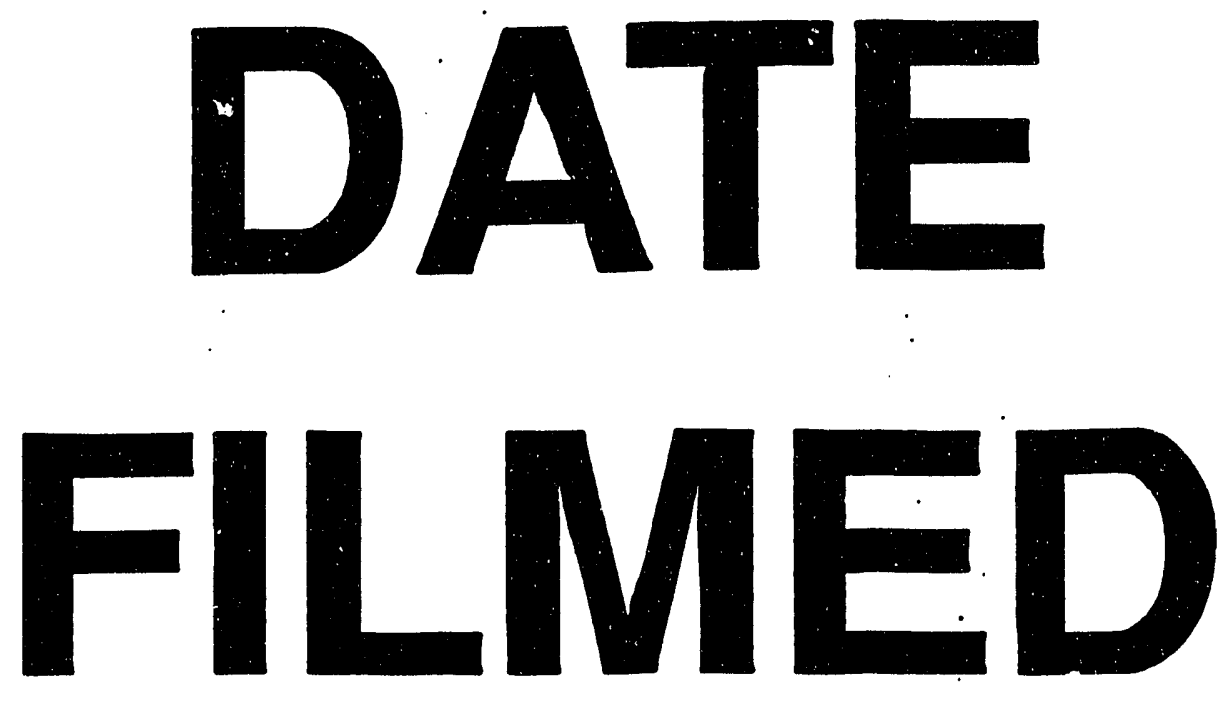

$10 / 19 / 93$
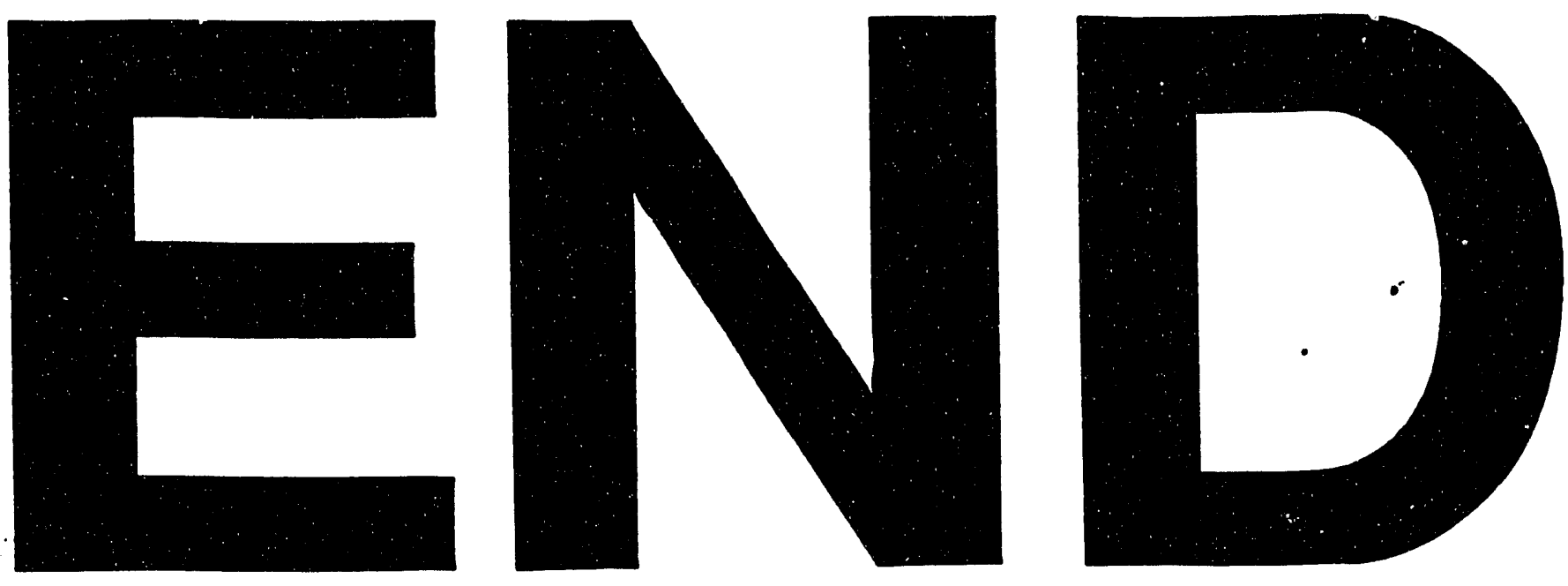
